Article

\title{
Improving Corrosion and Corrosion-Fatigue Resistance of AZ31B Cast Mg Alloy Using Combined Cold Spray and Top Coatings
}

\author{
Sugrib Kumar Shaha ${ }^{1, *}$, Siavash Borhan Dayani ${ }^{1}$, Yuna Xue ${ }^{1}$, Xin Pang ${ }^{2}$ and Hamid Jahed ${ }^{1}$ \\ 1 Department of Mechanical \& Mechatronics Engineering, University of Waterloo, 200 University Ave W, \\ Waterloo, ON N2L 3G1, Canada; sborhand@uwaterloo.ca (S.B.D.); xynlina@gmail.com (Y.X.); \\ hamid.jahed@uwaterloo.ca (H.J.) \\ 2 CanmetMATERIALS, Natural Resources Canada, 183 Longwood Road South, Hamilton, ON L8P 0A5, \\ Canada; xin.pang@canada.ca \\ * Correspondence: skumarsh@uwaterloo.ca
}

Received: 20 July 2018; Accepted: 26 November 2018; Published: 4 December 2018

check for updates

\begin{abstract}
In this paper, we report the application of zinc phosphate electrostatic-painting top coating on cold sprayed AA7075 leading to a significant improvement in corrosion-fatigue performance. High strength AA7075 powder was sprayed on AZ31B substrate, followed by the application of the top coating. The electrochemical corrosion and corrosion-fatigue tests of the coated and uncoated specimens were performed in $3.5 \% \mathrm{NaCl}$ solution. Transmission electron microscopy (TEM) analysis showed that a continuous nanolayered mixture of $\mathrm{Mg} / \mathrm{Al}$ was formed at the cold spray coating/substrate interface leading to high bonding strength. The results showed that the combined coatings improved the corrosion resistance remarkably, and significantly increased the fatigue life, with a fatigue strength of $80 \mathrm{MPa}$ at $10^{7}$ cycles, as compared to the as-cast specimen. Surface topographic analysis of the corrosion-fatigue-tested specimens demonstrated the presence of deep macro-pits on the cold sprayed AA7075 coating after 3.7 million cycles, while there were no such pits on the top-coated specimens, even after $10^{7}$ cycles when tested at $30 \mathrm{~Hz}$. The fractographic analysis of the fatigue-fractured specimens showed that the formation of pits allowed the $\mathrm{NaCl}$ solution to penetrate in the AZ31B substrate, creating localized corrosion pits resulting in premature failure, which eventually reduced the fatigue life.
\end{abstract}

Keywords: cold spray coating; e-paint; magnesium alloy; AA7075 alloy powder; corrosion-fatigue

\section{Introduction}

Magnesium (Mg) alloys are the lightest commercially available engineering materials and are attractive to automotive, aerospace and electronics industries for their potential to reduce the weight of various components [1]. However, they have high chemical reactivity and are susceptible to forming oxides, chlorides and sulfides, which results in poor corrosion resistance and limits their suitability for many applications. In the automotive industry to date, the use of $\mathrm{Mg}$ as a structural material has mainly been restricted to the trimming parts and certain structural components. To obtain the complete advantage of $\mathrm{Mg}$, its utilization needs to extend into load-bearing components [2]. The predominant barrier preventing the extension of the employment of $\mathrm{Mg}$ alloys is electrochemical reactivity, which is related to corrosion resistance, which results in restricting their performance in humid air and in aqueous environments [3-5]. This results in practical disputes associated with the utilization of $\mathrm{Mg}$ alloys in car manufacturing for the structural components that involve cyclic loading in practice. Therefore, the corrosion-fatigue resistance of $\mathrm{Mg}$ alloys needs to be significantly improved 
in order to take full advantage of the benefits of $\mathrm{Mg}$ alloys provide in light-weighting for transportation industries [6].

In general, wrought $\mathrm{Mg}$ alloys exhibit superior mechanical properties relative to as-cast materials [7-9]. However, the limited slip systems in $\mathrm{Mg}$ alloys at room temperature reduce their formability and hence complex-shaped parts cannot be made [2]. Therefore, for the manufacturing of parts with complex geometries, cast $\mathrm{Mg}$ alloys are more attractive for industrial applications $[1,10,11]$. Studies have reported that in the $\mathrm{Mg}$-Al systems, the $\mathrm{Mg}_{17} \mathrm{Al}_{12}$ possess a higher potential and a broader passivation range than the Mg-matrix, which diminishes the corrosion resistance by forming a galvanic cell with the $\alpha-\mathrm{Mg}$ matrix, leading to the formation of pits resulting in premature failure during cyclic loading [12]. At the same time, the presence of casting defects reduces the corrosion resistance and fatigue life as well. It is also well established that the rate of stress-corrosion cracking of magnesium alloys grow up with the presence of aluminum. The reported studies show that the fatigue life of $\mathrm{Mg}$ alloys in corrosive environments, such as seawater $(3.5 \% \mathrm{NaCl})$, are considerably lower than that in the air $[13,14]$. The corrosion-fatigue property of $\mathrm{Mg}$ alloys relies to a significant extent on the solution properties, specifically, on the $\mathrm{pH}$ of the solution. It has been shown that the aluminum (Al) content of the Mg alloy influences the alloy's stress-corrosion cracking behavior [15]. Die-cast and wrought $\mathrm{Mg}$ alloys with the lowest $\mathrm{Al}$ content, for example, AZ31B, exhibit the lowest extent of environmental effect in creep [16,17] and have the weakest fatigue behavior of relative to other Mg alloys [15,18].

$\mathrm{Mg}$ alloys are susceptible to form oxides at higher temperatures and in corrosive environments. Surface treatment processes require higher temperatures and liquid/melting (above $T_{\mathrm{m}}=650^{\circ} \mathrm{C}$ ) state are not suitable for $\mathrm{Mg}$ alloys. It has been stated that the environmental corrosion properties of $\mathrm{Mg}$ and its alloys can be enhanced by creating protective surface coatings in cold spray process [12,19-24] by introducing various types of coating materials that possess higher corrosion resistance, specifically, corrosion-fatigue resistance. In the Cold Spray (CS) process, coating particles are accelerated with the help of preheated gas at supersonic velocities, which then impact the substrate, resulting in the formation of dense coatings [25]. This process is suitable for materials that are chemically reactive and susceptible to oxidation, such as $\mathrm{Mg}$, as CS can be performed at low temperature and form lower porosity [26-28]. Al and their alloys powder have been recognized as wonderful coating materials that can be coated effectively the Mg substrates in the CS method. They are also extensively used for corrosion protection of the less noble metal substrates, due to their excellent corrosion resistance [29]. When $\mathrm{Al}$ is exposed to air, a thin layer of $\mathrm{Al}$ oxide is formed, which protects the material from oxygen penetration, thereby preventing further decays in corrosion or oxidation process. A number of studies has been completed to examine the coatings of $\mathrm{Al}$ and its alloys on $\mathrm{Mg}$ alloy substrates processed in CS system [12,19-24]. Yandouzi et al. [30] and Lee et al. [31] reported that although cold sprayed pure $\mathrm{Al}$ coatings obtained a better corrosion resistance than $\mathrm{Mg}$ substrates, their mechanical properties, especially coating/substrate bonding strength, have not reached the expected levels and still need to be improved for applying as a surface coating of Mg alloys [19]. Tao et al. [32,33] described that corrosion is the principal cause of the debilitated fatigue performance of AZ91D Mg alloy. They claimed that the corrosion resistance of AZ91D could be remarkably enhanced by making a coating of pure Al in CS method [32,33]. Diab et al. [12] studied the corrosion resistance and corrosion-fatigue performance of pure Al CS coatings deposited on extruded AZ31B Mg alloy. They achieved a significant improvement in corrosion resistance due to the $\mathrm{CS}$ of pure $\mathrm{Al}$, a marginal enhancement in fatigue properties in air and no improvement in corrosion-fatigue performance. In another study, investigators revealed that the pure $\mathrm{Al}$ coating deposited on AZ31B alloy extrusion upgraded its fatigue strength by $9 \%$ in the laboratory air [34]. They established that the small change in the fatigue performance of the coated substrate was obtained due to the low strength of the pure Al coating. Our recent study [35] demonstrates that the fatigue strength of the coated AZ31B cast Mg alloy in the air increased by $25 \%$ as a result of the deposition of AA7075 powder. The bonding strength also increased remarkably. In this circumstance, the coating material AA7075 plays a significant role in improving the fatigue life of the Mg substrate as an AA7075 alloy having high-strength; however, in corrosive environments, 
this improvement is lost. Therefore, a top-coat is proposed here to protect the material against corrosive environments.

In automotive industry applications, a top coating is usually applied to exposed parts. Many studies [36-41] have been conducted with the aim of finding suitable top coating materials for corrosion prevention of $\mathrm{Mg}$ alloys. A number of studies demonstrated that a variety of salts are suitable for corrosion prevention [40-42]. As zinc chromate provides better corrosion resistance than other pigments, it has been identified as the best option. However, the use of chromate has been banned because of detrimental impacts on the environment and its carcinogenicity [40,42]. Therefore, other zinc salts, which do not have harmful side effects, are of interest to researchers as alternative pigment materials. One pigment material that provides corrosion resistance that is similar to that of zinc chromate on different substrates is zinc phosphate [37-39]. Studies show that the corrosion resistance of $\mathrm{Mg}$ alloys can be improved significantly by using zinc phosphate top coats on the $\mathrm{Mg}$ alloy substrates in a corrosive environment [36]. Thus, zinc phosphate has been selected for this study as the pigment for top coating on the CS coated specimens.

As indicated in the above literature review, most studies in the scientific literature have focused on the corrosion behavior of $\mathrm{CS}$ coatings of pure $\mathrm{Al}$ and $\mathrm{Al} / \mathrm{Al}_{2} \mathrm{O}_{3}$ or $\mathrm{Al} / \mathrm{Mg}_{17} \mathrm{Al}_{12}$ composites on $\mathrm{Mg}$ alloy substrates. To the authors' knowledge, there have been no studies on the corrosion and corrosion-fatigue behavior of a high-strength CS AA7075 alloy deposited on the Mg alloy substrate. It is also not clear how the fatigue properties of the coating behave in a corrosive environment if an additional top coating, such as of zinc phosphate in the electrostatic-painting process (e-painting), is added to the CS coating. In the present study, the electrochemical corrosion and corrosion-fatigue properties of the CS AA7075 alloy on the as-cast AZ31B substrate are investigated in uncoated specimens, coated specimens and specimens that were coated then e-painting in a $3.5 \% \mathrm{NaCl}$ solution. The fracture mechanisms were studied through observations of the fracture surfaces under selected conditions using an X-ray diffractometer and a scanning electron microscope (SEM).

\section{Experimental Details}

\subsection{Materials and Coating Methods}

In this study, as-cast AZ31B Mg alloy was used as the substrate. An Al-based wrought alloy, AA7075, which has a higher strength and longer fatigue life than AZ31B was used as the coating materials. The chemistry of both substrate (AZ31B) and the coating powder (AA7075) is presented in Table 1. The spherical shape AA7075 powder was delivered by Centerline Ltd., Windsor, ON, Canada. Details about the characteristics of the coating material can be found in our earlier paper [35].

Table 1. Chemical composition (wt \%) of the AZ31 cast alloy and the AA7075 coating powder.

\begin{tabular}{ccccccccc}
\hline Alloy & $\mathbf{M g}$ & $\mathbf{A l}$ & $\mathbf{Z n}$ & $\mathbf{M n}$ & $\mathbf{C u}$ & $\mathbf{F e}$ & $\mathbf{C r}$ & Others \\
\hline AZ31 & balance & 3.29 & 1.33 & 0.37 & 0 & 0 & 0 & $>0.01$ \\
AA7075 & 2.35 & balance & 5.2 & 0 & 1.55 & 0.35 & 0.25 & 0.3 \\
\hline
\end{tabular}

The CS coating was deposited in the Fatigue and Stress Analysis laboratory, University of Waterloo, Waterloo, Canada, utilizing the low pressure Supersonic Spray Technologies (SST) Series P CS system made by Centerline Ltd., Windsor, ON, Canada. First, $70 \mathrm{~mm}$ length dog bone shape test specimens were extracted from the as received cast billet maintaining ASTM: E8/E8M-11 [43]. The diameter of the billet was 300-mm. Then, the extracted specimen surfaces were polished using 320, 400 and 600-grid $\mathrm{SiC}$ emery paper and washed with acetone. To obtain the critical velocity of the AA7075 particles through the converging-diverging DeLaval nozzle in the low-pressure CS system, commercially available nitrogen gas was introduced as a carrier gas. The coating was performed in parallel passes along the lengthwise of the specimens. To achieve full coverage a step-over of $1.2 \mathrm{~mm} / \mathrm{step}$ was considered in each pass of the CS method. Details of the coating parameters can be found in [35]. 
Many types of top coating methods are available in the automotive industry. Among them, electrostatic painting, commonly known as e-painting or e-coating, was selected for this study because of its deposition efficiency and wide availability. The e-coating was performed at MetoKote in Cambridge, ON, Canada. This process has been mentioned as e-painting in some references [44]. The exact chemical composition is MetoKote's proprietary information. The uncoated AZ31B and the specimen coated with AA7075 by CS were subject to e-painting with zinc phosphate. The CS coated specimens were polished using emery paper to achieve a surface roughness of up to $10 \mu \mathrm{m}$, which was measured at University of Waterloo, Waterloo, Canada using 3D Laser Scanning Confocal Microscope VK-X250 (Keyence, Osaka, Japan. The specimens were hung on the painting line with a conductive hanger for subsequent e-painting. Figure 1 shows the major steps of the e-painting process, which was adopted from Metokote [44].

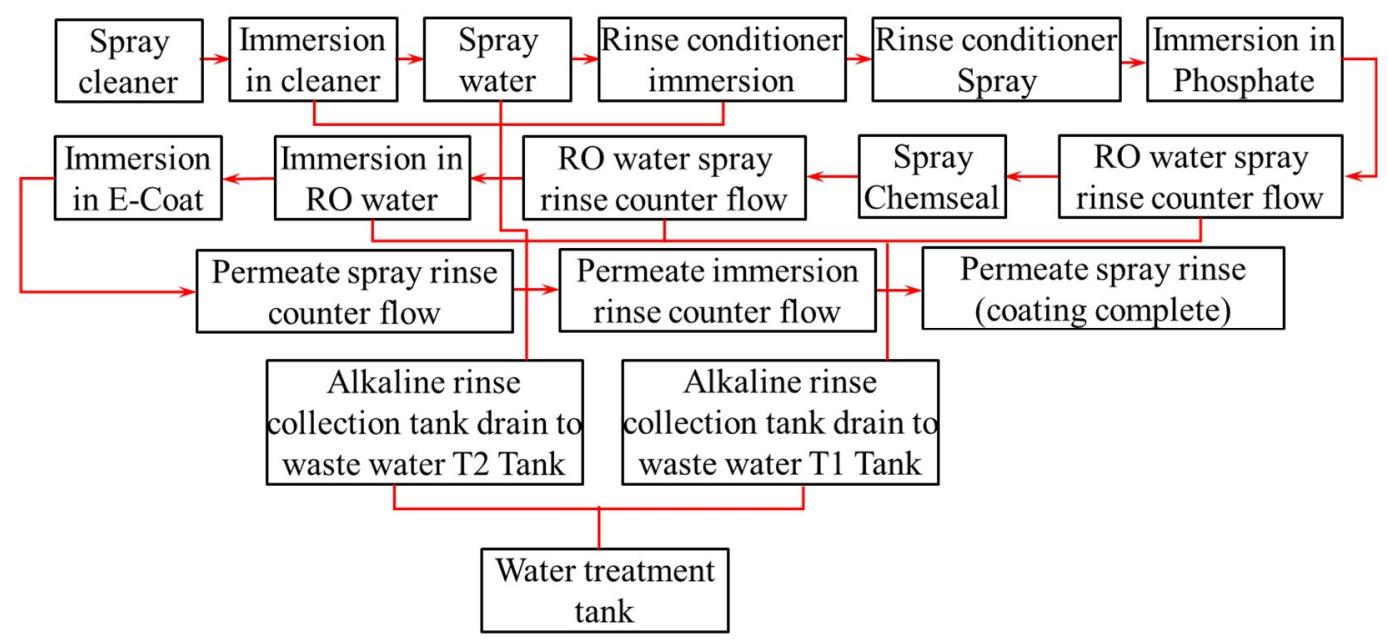

Figure 1. The different steps applied in e-painting process in this study (adapted from Metokote [44]). Note: RO-reverse osmosis.

\subsection{Microstructural Analysis}

The coated and EP specimen was cross-sectioned, mounted and polished following standard metallographic techniques as described in ASTM E3. Microstructural analysis was performed using an SEM (model: FEI Quanta FEG 250 ESEM, Thermo Fisher, Waltham, MA, USA) equipped with an Oxford energy-dispersive X-ray spectroscopy (EDX). Thin foils $(<100 \mathrm{~nm})$ were made using a focused ion beam (FIB, Zeiss NVision40, Oberkochen, Germany) combined with Schottky field emission SEM. Then, the thin foils were examined using transmission electron microscopy (TEM, Tecnai Osiris, Model LVEM5, Santa Clara, NE, USA), JEOL-2010F (Tokyo, Japan) furnished with EDX and operated at a voltage of $200 \mathrm{kV}$.

\subsection{Electrochemical Corrosion Test}

The electrochemical corrosion testing of the uncoated, CS AA7075 coated and CS AA7075 followed by EP (CS + EP) coated AZ31B Mg alloy specimens was performed in a $3.5 \mathrm{wt} . \% \mathrm{NaCl}$ solution at room temperature using a Solartron Analytical 1287A potentiostat/galvanostat and a Solartron 1255B frequency response analyzer (AMETEK, Inc., Berwyn, PA, USA). A conventional three-electrode setup was adopted, with the specimen to be examined as the working electrode, $\mathrm{Ag} / \mathrm{AgCl}$ in a saturated $\mathrm{KCl}$ solution as the reference electrode and a platinum plate as the counter electrode. The exposed surface area of the $\mathrm{Mg}$ alloy specimen was $1 \mathrm{~cm}^{2}$. Advanced electrochemical techniques including the open circuit potential (OCP) measurement, electrochemical impedance spectroscopy (EIS) and potentiodynamic polarization were conducted. The EIS test was performed at a frequency range of $0.1-100 \mathrm{kHz}$ at the OCP with perturbation signal amplitude of $10 \mathrm{mV}$. The EIS results were presented as Bode plots and the obtained data were analyzed using ZSimpWin software version 3.50 and interpreted 
based on an equivalent electrical circuit, as shown in Figure 2. Here, $Q_{\mathrm{dl}}$ is double layer capacitance, $R_{\mathrm{ct}}$ is charge transfer resistance, $L_{\mathrm{ads}}$ is adsorption inductance and $R_{\mathrm{ads}}$ is adsorption resistance, while $Q_{\text {coat }}$ is capacitance, $R_{\text {coat }}$ is coating layer resistance, $Q_{\mathrm{dl}}$ is capacitance, and $R_{\mathrm{ct}}$ is charge transfer resistance. Details about the equivalent electrical circuit can be found in [45]. After OCP and EIS test, the potentiodynamic polarization measurements were conducted at a scan rate of $1 \mathrm{mV} \cdot \mathrm{s}^{-1}$, from $-200 \mathrm{mV}$ to approximately $+1000 \mathrm{mV}$ versus OCP. A Tafel fit of the potentiodynamic curve in the potential range of 80 to $180 \mathrm{mV}$ away from $E_{\text {corr }}$ was conducted and the corrosion rate was calculated based on the fitting results. For each condition, the electrochemical tests were repeated at least three samples on the fresh surface to ensure reproducibility, and the representative graphs are presented. All corrosion tests were performed at the CanmetMATERIALS corrosion laboratory in Hamilton, ON, Canada.
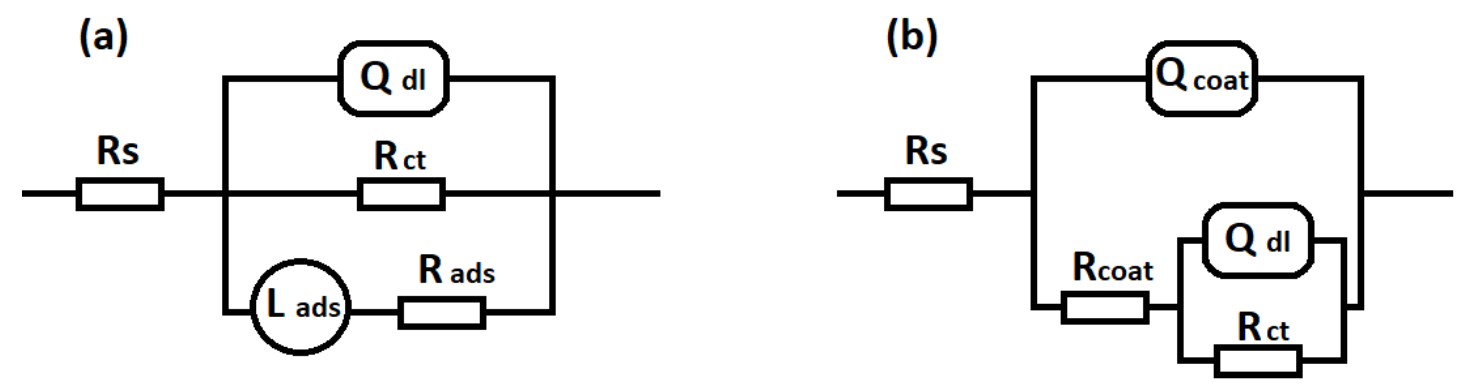

Figure 2. Equivalent electrical circuits for (a) uncoated and (b) coated AZ31B alloy specimens.

\subsection{Tensile and Corrosion-Fatigue Testing}

Tensile test of the samples were performed following ASTM E8 standard [43]. The corrosion fatigue tests were performed on four groups of AZ31B samples: (1) uncoated, (2) e-painted (EP) only, (3) CS AA7075 coated only, and (4) CS AA7075 followed by e-painting (CS + EP). Hourglass shape round bar with $7 \mathrm{~mm}$ minimum diameter was used as a fatigue testing specimen. The dimension of the fatigue testing specimens and coating thickness of the specimens are given in previous paper [35]. The fatigue tests were performed using an Instron RR Moore four-point rotating-bending fatigue testing machine (Norwood, MA, USA) in fully reversed $(R=-1)$ load controlled condition. This is achieved by controlling the bending moment in the gage section, which causes the maximum stress at the surface of the specimens. The tests were conducted at different stress amplitudes between 40 and $140 \mathrm{MPa}$ with a step size of $20 \mathrm{MPa}$, covering both low and high cycle regimes. To find the fatigue strength at $10 \mathrm{M}$ cycle staircase method was used. A customized corrosion chamber was installed on the fatigue machine, which was used to perform the corrosion-fatigue test. Details on the design of the chamber can be found in [12]. The chamber allowed a continuous flow of $3.5 \% \mathrm{NaCl}$ solution onto the specimen gauge section at a constant rate of $40 \mathrm{~mL} \cdot \mathrm{min}^{-1}$ during the fatigue testing. It was confirmed that the flow rate of the solution was enough to form a continuous thin film of $\mathrm{NaCl}$ solution on the surface of the specimen gauge throughout the duration of the test. The solution was supplied from a reservoir to the chamber using a pipe and a valve was used to control the flow rate. The solution that gathered at the bottom of the chamber was disposed. To avoid the galvanic corrosion of the specimen near the fatigue machine-bearing housing collets, silicon resin was applied to the specimen grip section. For all fatigue tests, a constant frequency of $30 \mathrm{~Hz}$ was maintained and tests were stopped either when specimens break apart, or upon reaching $10 \mathrm{M}$ cycles. At least two samples were tested for each stress level. The fatigue fracture surfaces were then characterized using an XRD and SEM. The XRD analysis was performed using Bruker D8 (Billerica, MA, USA) discover machine equipped with 2D detector, while environmental SEM equipped with oxford EDX were used to analysis the fatigue fracture surfaces. 


\section{Results}

\subsection{Microstructure}

Figure 3 shows the SEM micrographs of the polished cross-section of the specimens e-painted on the substrate and CS AA7075. As seen in Figure 3, the e-paint (EP) thickness was $20 \mu \mathrm{m}$ in both cases: the uncoated AZ31B and the CS AA7075 on AZ31B substrate. The observed porosity in the microstructure of EP layer was formed during specimen preparation polishing. The AA7075 coated specimen exhibited almost pore-free coatings (Figure $3 \mathrm{~b}$ ). The obtained CS coating thickness in the as-processed condition was $282 \pm 26.11 \mu \mathrm{m}$, while the thickness was $122 \pm 3.85 \mu \mathrm{m}$ following grinding of the outer surface with a roughness $R_{\mathrm{a}}$ of 2.6 and $0.37 \mu \mathrm{m}$, respectively. The BF and HAADF-STEM images with the EDX line scan near the interface are presented in Figure 4 . As seen clearly in Figure 4b, there are three distinguished zones: (A) the $\mathrm{Mg}$ substrate, (B) the interface and (C) the AA7075 coating. A continuous layer (marked by blue arrow) with a thickness of 200-300 nm was identified between the coating and the substrate. The EDX line scan confirmed that the layer contains a mixture of Mg and Al. An obvious grain refinement was observed at the interface. The grain size obtained near the interface was $\sim 200 \mathrm{~nm}$ after CS (as seen in Figure 4c), while the grain size of the as-cast substrate is $\sim 278 \mu \mathrm{m}$ [11]. The elongated ladder-like grains are observed in CS AA7075 coating with MgZn 2 precipitates along the grain boundaries, as indicated by the red arrows in Figure $4 \mathrm{~d}$. Also, columnar grains were detected in the interfacial region (Figure 4a). A similar type of TEM microstructure obtained through CS of the AZ31B alloy was reported in [46].
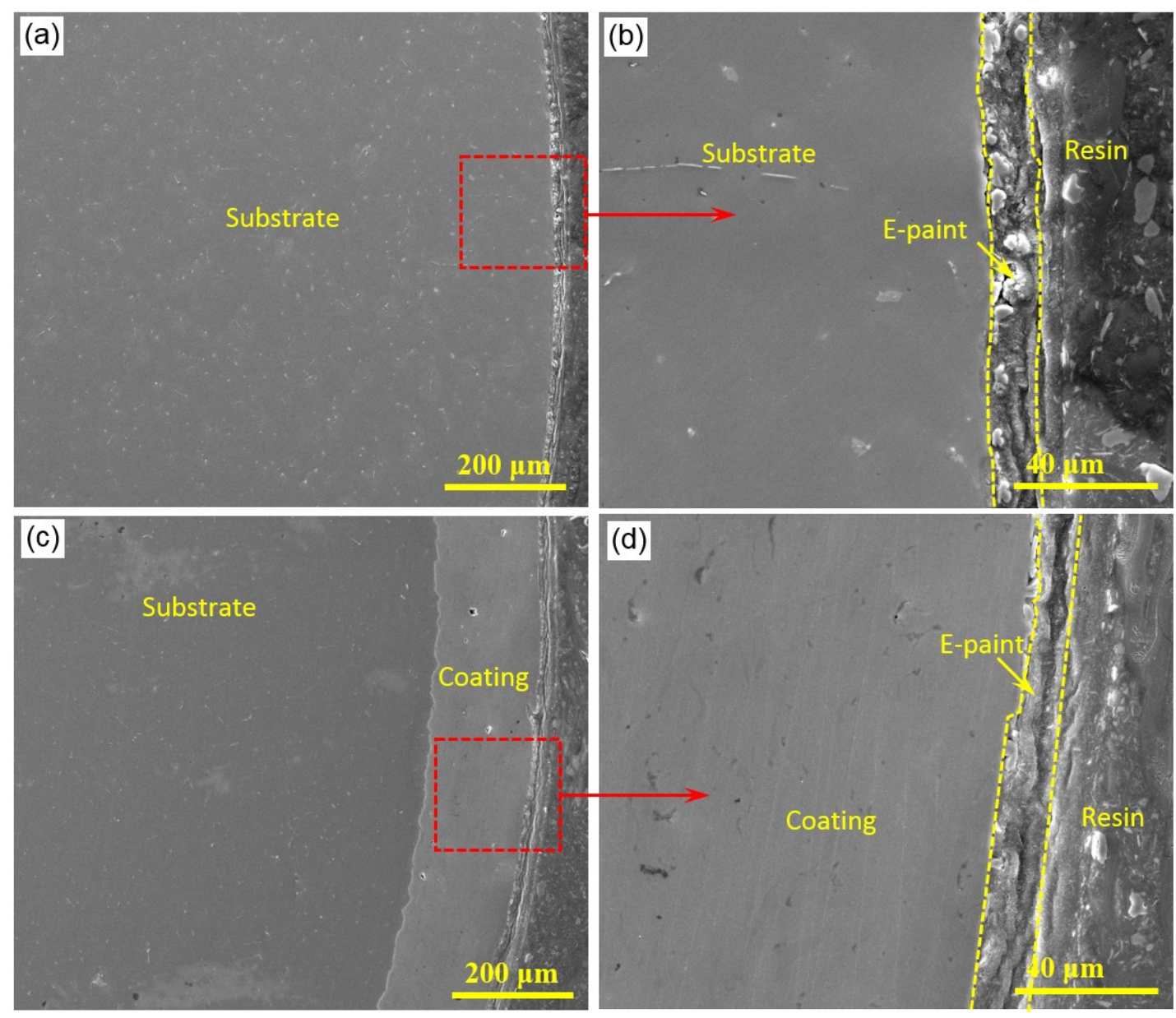

Figure 3. Scanning electron microscopy (SEM) images show the polish-cross section of AZ31B Mg alloy with $(\mathbf{a}, \mathbf{b})$ e-painted on AZ31B and (c,d) e-painted on cold spray AA7075. 

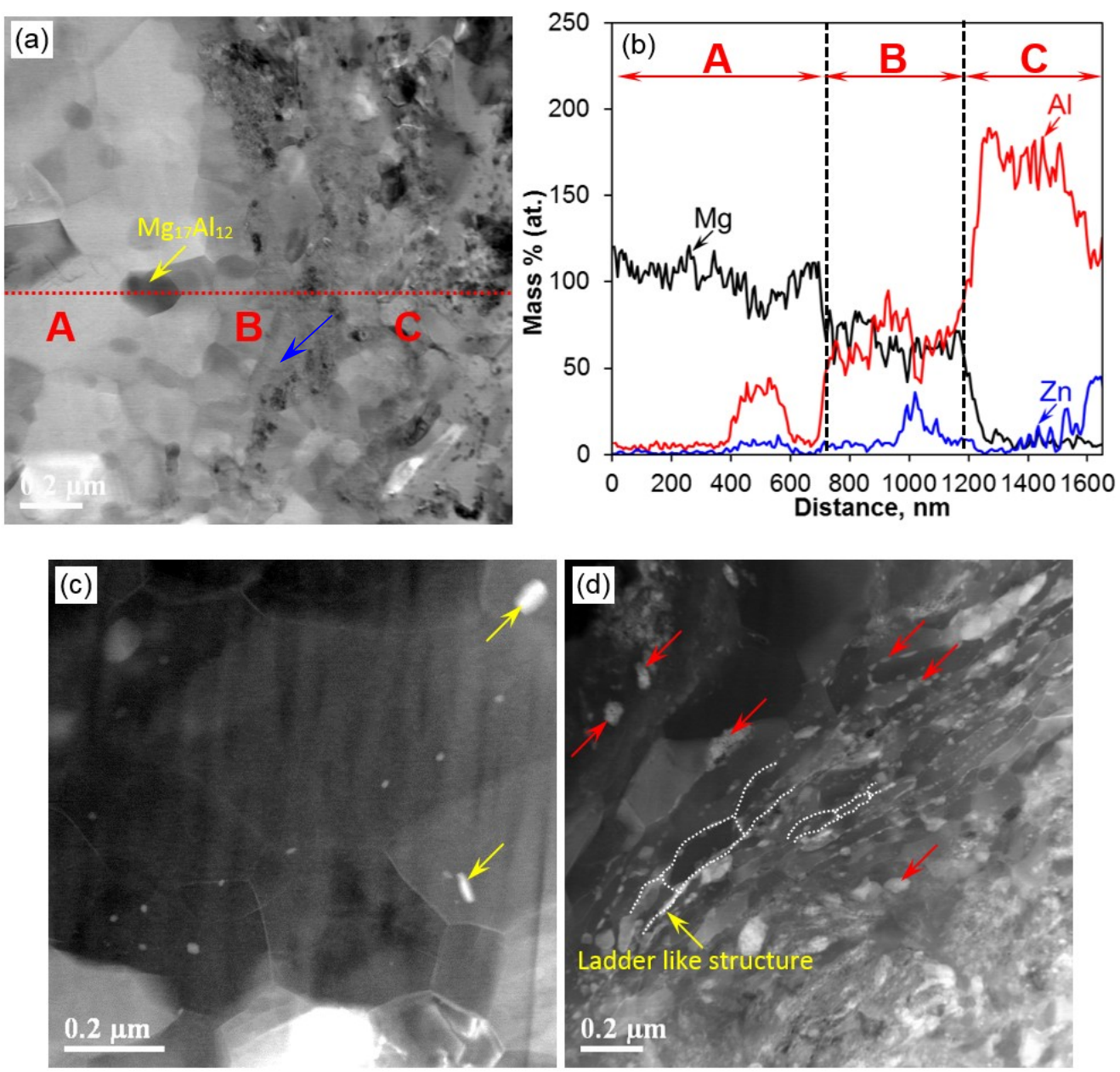

Figure 4. Transmission electron microscopy (TEM) micrographs show the different zones of the cold spray (CS)-coated specimen: substrate (A), interface (B) and coating (C) of AZ31B alloy coated with AA7075 alloy in different modes: (a) bright field image, with (b) EDX line scan, STEM-High-angle annular dark-field (HAADF) image of (c) substrate and (d) coating Note: Yellow arrows- $\mathrm{Mg}_{17} \mathrm{Al}_{12}$, Red arrows- $\mathrm{MgZn}_{2}$, white line-ladder like grains. The raw data required to reproduce these findings are available to download from http:/ /dx.doi.org/10.17632/5b5rk27wmx.1.

\subsection{Electrochemical Corrosion Behavior}

\subsubsection{Open Circuit Potential (OCP)}

Figure 5a shows the OCP values of uncoated, CS AA7075 coated and CS + EP coated AZ31B specimens immersed in a $3.5 \% \mathrm{NaCl}$ solution for $30 \mathrm{~min}$. It is clearly seen that the CS + EP coated specimen has significantly nobler OCP values compared to the other two specimens with a steady state potential of $-1.07 \mathrm{~V}$, indicating very low thermodynamic tendency of corrosion owing to the protection of the dual-layer coating. The uncoated AZ31B exhibits a constant but the most negative OCP value of $-1.58 \mathrm{~V}$ over the $30 \mathrm{~min}$, which implies very high corrosion tendency. In contrast, the CS AA7075 alloy showed a slight initial potential drop likely related to the destruction of a virgin aluminum oxide film formed during the cold spray process and then a gradual increase to a steady state at $-1.34 \mathrm{~V}$ due to the formation of a stable oxide film in the salt solution. A similar OCP behavior of CS pure $\mathrm{Al}$ on AZ91D alloy was reported in literature $[47,48]$. 

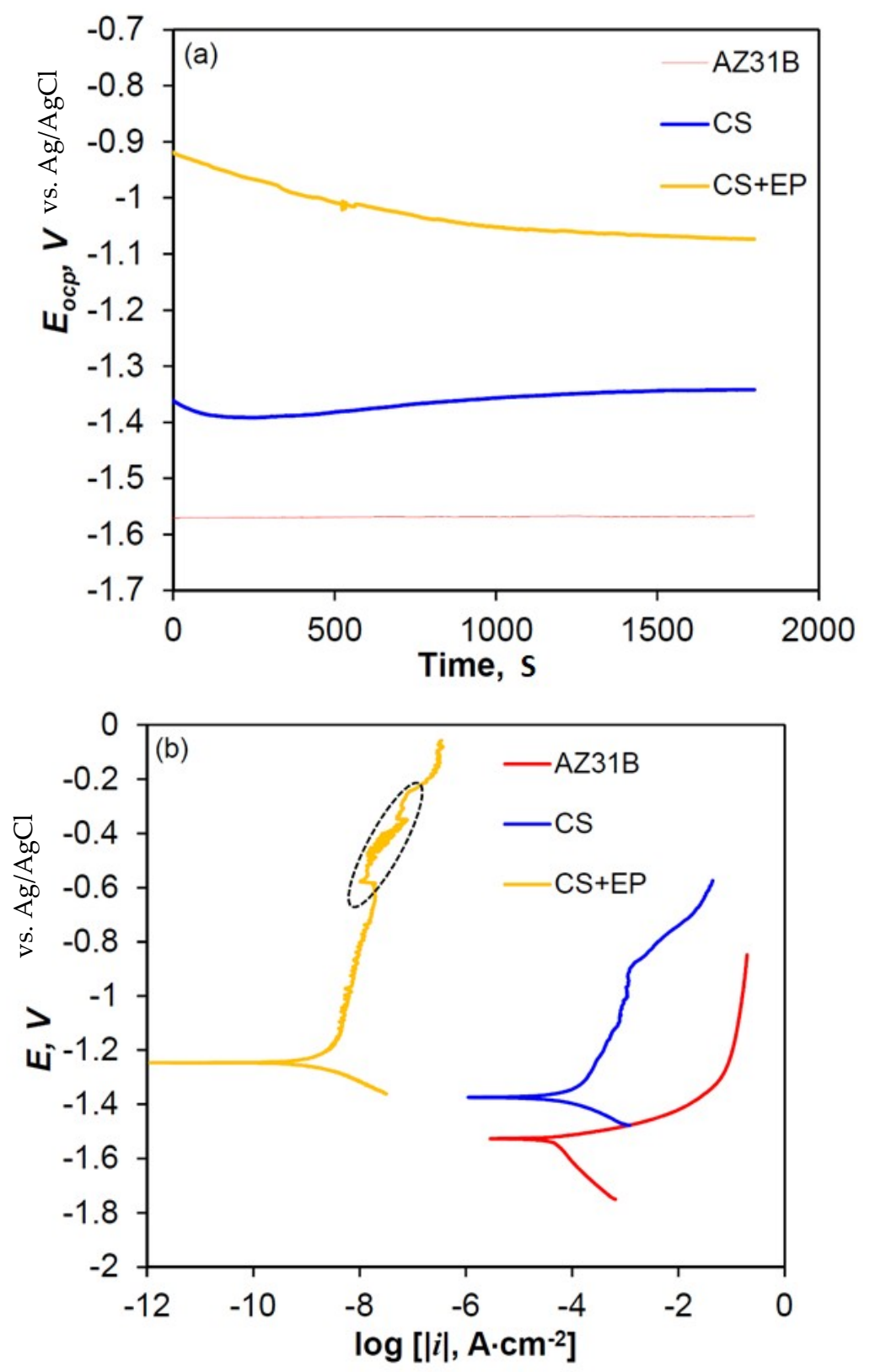

Figure 5. The (a) Open circuit potential (OCP) and (b) polarization curves of uncoated, CS AA7075 coated and CS + EP coated AZ31B specimens.

\subsubsection{Potentiodynamic Polarization}

Prior to the potentiodynamic polarization test, all specimens were immersed in the salt solution for $30 \mathrm{~min}$ to reach their stable OCP and after their EIS test. The potentiodynamic polarization curves of the uncoated and coated specimens in a $3.5 \% \mathrm{NaCl}$ solution are shown in Figure $5 \mathrm{~b}$. All curves showed cathodic and anodic Tafel behavior around the corrosion potential, i.e., a smooth and linear change of current density with potential. To obtain the corrosion current, the data from the polarization curves within $E_{\text {corr }}, \pm 80-180 \mathrm{mV}$ were analyzed following the Tafel extrapolation method [49]. In this potential range, the relationship between the measured current density $i$ and electrode potential $E$ follows the Wagner-Traud equation [50]:

$$
i=i_{\text {corr }}\left[\exp \left(2.303 \frac{E-E_{\text {corr }}}{b_{a}}\right)-\exp \left(-2.303 \frac{E-E_{\text {corr }}}{b_{c}}\right)\right.
$$


where $i_{\text {corr }}, b_{\mathrm{a}}, b_{\mathrm{c}}$ and $E_{\mathrm{corr}}$ are corrosion current density, anodic Tafel constant, cathodic Tafel constant and corrosion potential, respectively. The calculated parameters for the $\mathrm{Mg}$ alloy specimens are listed in Table 2. The corrosion rate (CR) in mm/year is calculated through Faraday's law [51]:

$$
\mathrm{CR}=K_{1} \frac{i_{\text {corr }}}{\rho} \mathrm{EW}
$$

where $i_{\text {corr }}$ is in $\mu \mathrm{A} \cdot \mathrm{cm}^{-2}, K_{1}=3.27 \times 10^{-3} \mathrm{~mm} \cdot \mathrm{g} / \mu \mathrm{A} \cdot \mathrm{cm} \cdot$ year, $\rho$ (density) $=1.738 \mathrm{~g} \cdot \mathrm{cm}^{-3}$ and $\mathrm{EW}=12.15$ for Mg. The results show that CS + EP coated AZ31B exhibits superior corrosion resistance than the uncoated and CS coated specimens. The uncoated AZ31B (substrate) exhibited the highest $i_{\text {corr value }}\left(117.6 \mu \mathrm{A} \cdot \mathrm{cm}^{-2}\right)$ and the lowest $E_{\text {corr }}(-1.52 \mathrm{~V})$ and thus had the lowest corrosion resistance. The anodic curve of the uncoated AZ31B showed active dissolution behavior and no active-passive transition. The application of CS coating led to a reduction in the corrosion current and a positive shift of the corrosion potential, which manifested the protectiveness of the coating against corrosion. Much more robust corrosion protection was seen on the CS + EP coated specimen, for which a corrosion rate three orders of magnitude lower than that of the uncoated substrate was observed (Table 2).

Table 2. Tafel fitting results for the uncoated, cold spray (CS) AA7075 coated and CS + EP coated AZ31B alloy specimens.

\begin{tabular}{cccc}
\hline Specimens & $\boldsymbol{E}_{\text {corr }}(\mathrm{V})$ & $\boldsymbol{i}_{\text {corr }}\left(\boldsymbol{\mu A} \cdot \mathrm{cm}^{-2}\right)$ & Corrosion Rate $(\mathrm{mm} /$ year) \\
\hline Uncoated & -1.52 & 117.6 & 2.7 \\
CS & -1.37 & 80.7 & 1.8 \\
CS + EP & -1.24 & $7 \times 10^{-2}$ & $1.6 \times 10^{-3}$ \\
\hline
\end{tabular}

It is worth mentioning that at potentials higher than $-0.6 \mathrm{~V}$ the CS + EP coated specimen showed obvious oscillations of current density (enclosed by the black dotted line), which may be caused by local breach of the coating protection at weak spots or defects of the EP layer. This may affect the fatigue performance of the CS + EP coated specimen in corrosive environments, which will be discussed later in the paper.

\subsubsection{Electrochemical Impedance Spectroscopy (EIS) Characteristic}

EIS technique is a powerful tool that is commonly used to study the protectiveness of coatings. In this work, the corrosion behavior of uncoated and coated AZ31B Mg alloy specimens was investigated using EIS and the results are presented in Figure 6 in the form of the Bode plot. Prior to the EIS measurement, the specimens were immersed in the $3.5 \% \mathrm{NaCl}$ solution for $30 \mathrm{~min}$ to achieve a stable OCP. The EIS behavior of the specimens at low frequencies can be correlated to the corrosion resistance of the surface associated with the presence of oxide film or hydration [52]. As reported in [53], during immersion the hydrated or oxide film can act as an electric barrier hindering the electric charge transfer through the film. The efficiency of this barrier completely depends on the density and stability of the film. As shown in Figure 6a, the impedance modulus of the CS + EP coated AZ31B Mg alloy is much higher than that of the CS coated and uncoated AZ31B specimens, which indicates that a thick insulating barrier layer was formed on the EP + CS coated specimen, resulting in superior corrosion resistance.

The equivalent electric circuit models presented in Figure 2 were utilized for simulation of the EIS response of the uncoated and coated Mg alloy specimens. For the uncoated AZ31B, the equivalent circuit consists of charge transfer resistance $\left(R_{\mathrm{ct}}\right)$, double layer capacitance $\left(Q_{\mathrm{dl}}\right)$, adsorption resistance $\left(R_{\mathrm{ads}}\right)$ and adsorption inductance $\left(L_{\mathrm{ads}}\right)$ [45]. The $Q_{\mathrm{dl}}$ and $R_{\mathrm{ct}}$ are associated with the Faradaic processes that take place at the interface of the solution and the electrode surface and the $L_{\text {ads }}$ and $R_{\text {ads }}$ can be attributed to the formation of a partially protective surface layer on the $\mathrm{Mg}$ alloy. In contrast, the equivalent circuit for the coated specimens (Figure $2 \mathrm{~b})$ consists of coating layer resistance $\left(R_{\text {coat }}\right)$ and capacitance $\left(Q_{\text {coat }}\right)$ and the charge transfer resistance $\left(R_{\mathrm{ct}}\right)$ and double layer capacitance $\left(Q_{\mathrm{dl}}\right)[54]$. 
Note that in the equivalent models the constant phase element (CPE) was used to fit the electrochemical system. The impedance $(Z)$ of the $C P E$ is given by:

$$
Z^{-1}=Q_{0}(j \omega)^{n}
$$

where $\omega$ is the angular frequency, $Q_{0}$ is the admittance at $\omega=1 \mathrm{rad} \cdot \mathrm{s}^{-1}, j$ is the imaginary number and $n$ is the CPE power. The factor $n$ is typically between 0.5 and 1.0 [55]. The flattening of the peak value in the phase angles-frequency curves provides evidence for better corrosion resistance. Similar corrosion behavior was reported by Nady et al. [56] for the different types of materials. When $n=1$, a CPE is equivalent to an ideal capacitor. The simulated EIS response for all specimens was also plotted in line in Figure 6. A good agreement between the fitted lines and the EIS data (points) is seen. The obtained simulation parameters for the electric circuit components are listed in Tables 3 and 4.
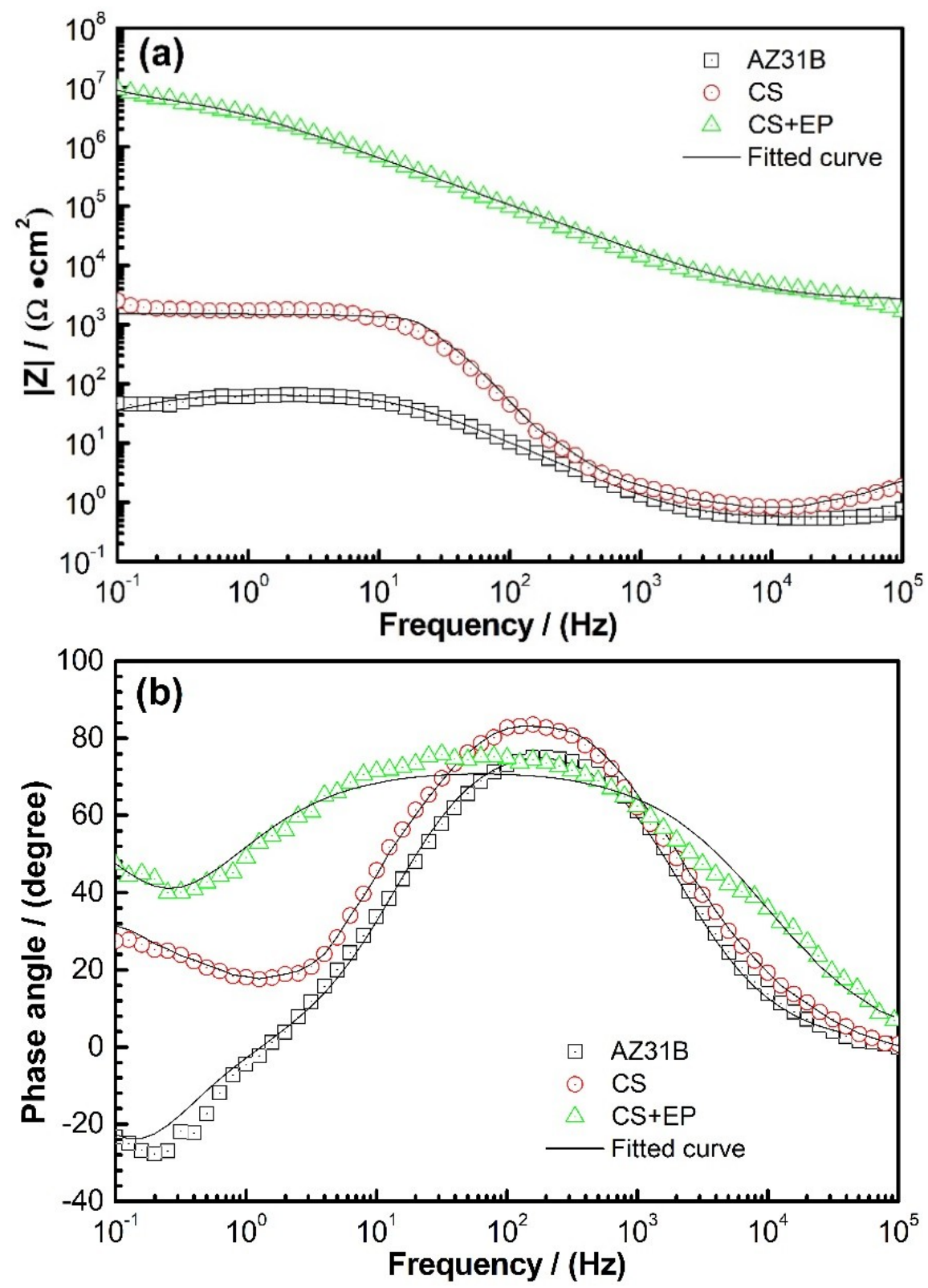

Figure 6. The electrochemical impedance spectroscopy (EIS) data in Bode plot of (a) impedance modulus $|Z|$ versus frequency and (b) phase angle versus frequency curves for uncoated, CS AA7075 coated and CS + EP coated AZ31B Mg alloy specimens. 
Table 3. The EIS simulation results for the uncoated AZ31B Mg alloy tested in $3.5 \% \mathrm{NaCl}$ solution.

\begin{tabular}{cccccc}
\hline Specimen & $\boldsymbol{R}_{\mathrm{ct}}\left(\boldsymbol{\Omega} \cdot \mathrm{cm}^{2}\right)$ & $\begin{array}{c}Q_{\mathrm{dl}} \\
\left(\mu \mathrm{F} \cdot \mathrm{cm}^{-2} \cdot \mathrm{s}^{n-1}\right)\end{array}$ & $n_{\mathrm{dl}}$ & $\boldsymbol{R}_{\mathrm{ads}}\left(\boldsymbol{\Omega} \cdot \mathrm{cm}^{2}\right)$ & $\begin{array}{c}L_{\mathrm{ads}} \\
\left(\mathbf{m H} \cdot \mathbf{c m}^{-2}\right)\end{array}$ \\
\hline uncoated & $1.64 \times 10^{2}$ & 23.59 & 0.95 & $1.45 \times 10^{2}$ & 0.786 \\
\hline
\end{tabular}

Table 4. The EIS simulation results for the CS + EP coated AZ31B Mg alloy.

\begin{tabular}{ccccccc}
\hline Specimen & $\begin{array}{c}Q_{\text {coat }} \\
\left(\mu \mathrm{F} \cdot \mathbf{c m}^{-\mathbf{2}} \cdot \mathbf{s}^{\boldsymbol{n}-\mathbf{1})}\right.\end{array}$ & $\boldsymbol{n}_{\text {coat }}$ & $\begin{array}{c}\boldsymbol{R}_{\text {coat }} \\
\left(\boldsymbol{\Omega} \cdot \mathbf{c m}^{\mathbf{2}}\right)\end{array}$ & $\boldsymbol{R}_{\mathrm{ct}}\left(\boldsymbol{\Omega} \cdot \mathrm{cm}^{2}\right)$ & $\begin{array}{c}Q_{\mathrm{dl}} \\
\left(\mu \mathrm{F} \cdot \mathrm{cm}^{-2} \cdot \mathbf{s}^{n-1}\right)\end{array}$ & $\boldsymbol{n}_{\mathrm{dl}}$ \\
\hline CS & 0.13720 & 0.87 & $1.833 \times 10^{2}$ & $1.42 \times 10^{3}$ & 0.92 & 0.58 \\
CS + EP & 0.05301 & 0.81 & $8.756 \times 10^{6}$ & $4.13 \times 10^{7}$ & 0.21 & 0.41 \\
\hline
\end{tabular}

For the uncoated AZ31B, a $R_{\mathrm{ct}}$ of $164 \Omega \cdot \mathrm{cm}^{2}$ and $Q_{\mathrm{dl}}$ of $\sim 24 \mu \mathrm{F} \cdot \mathrm{cm}^{-2} \cdot \mathrm{s}^{n-1}$ were obtained (Table 3). In the case of magnesium corrosion, the inductive behavior at low frequencies may be associated with the presence and adsorption of $\mathrm{Mg}^{+}$or $\mathrm{Mg}^{2+}$ ions from the corrosion processes on the metal surface. In this work, a higher than normal $L_{\text {ads }}$ value was obtained for the uncoated AZ31B, which may be attributed to the instability of the system commonly seen for Mg alloys. The corrosion rate of the specimens is proportional to the reciprocal of their $R_{\mathrm{ct}}$ values [57,58]. As depicted in Table 4, the CS coated specimen exhibited a higher $R_{\mathrm{ct}}$ compared to the uncoated alloy, which demonstrates that the CS AA7075 coating resulted in improved corrosion resistance. The CS + EP coated specimen showed a $R_{\mathrm{ct}}$ over five orders of magnitude higher than that of the uncoated AZ31B. The $n_{\mathrm{dl}}$ values for the coated specimens are close to 0.5 , which is indicative of a diffusion-controlled process in the double layer region. Apparently the $R_{\mathrm{ct}}$ value of $\sim 41.3 \mathrm{M} \Omega \cdot \mathrm{cm}^{2}$ for the CS + EP coated specimen manifests the insulting and thence protective nature of the coating, considering the fact that ultrapure water with a specific resistance of $18.2 \mathrm{M} \Omega \cdot \mathrm{cm}^{2}$ is considered an insulator. With the CS AA7075 coating the $\mathrm{Mg}$ alloy was expected to have better corrosion resistance. However, the underperformance of the CS coated AZ31B, as discussed later, may be attributed to several different factors including but not limited to corrosion performance of AA7075, localized pit formation and the presence of residual stress.

\subsection{Tensile Properties}

The tensile properties of the coated and uncoated specimens were evaluated at air in laboratory condition. The tensile test results are presented in Table 5 . The obtained results show that the as-cast AZ31B specimen achieved a YS of $87 \mathrm{MPa}$, an ultimate tensile strength (UTS) of $196 \mathrm{MPa}$ and an elongation of $12 \%$ during quasi-static tensile loading. In contrast, the CS specimens show significantly higher YS values of $110 \mathrm{MPa}$, while the UTS is 197 MPa. However, the CS and CS + EP specimens exhibited similar tensile properties.

Table 5. Tensile properties of the uncoated, CS AA7075 coated, and CS + EP samples.

\begin{tabular}{cccc}
\hline Sample ID & YS (MPa) & UTS (MPa) & Fracture Strain (\%) \\
\hline \multirow{2}{*}{ Uncoated } & 88.75 & 195.88 & 11.32 \\
& 85.50 & 196.25 & 13.26 \\
CS & 112.65 & 194.56 & 12.15 \\
& 107.50 & 199.21 & 11.88 \\
CS + EP & 108.95 & 196.43 & 10.97 \\
& 113.25 & 195.78 & 12.84 \\
\hline
\end{tabular}

\subsection{Corrosion-Fatigue Behavior}

Figure 7 depicts the $S-N$ curves of the coated and uncoated specimens tested in $3.5 \% \mathrm{NaCl}$ solution at different stress amplitudes. The results of the fatigue test on the AZ31B cast in the air is 
also shown in Figure 7 to demonstrate the effectiveness of coatings in protecting AZ31B from the corrosive environment.

In general, the specimen CS + EP (AZ31B-cast-CSAA7075-EP) exhibited superior fatigue life compared to the other conditions. The fatigue strength of EP and the CS + EP specimens increased considerably in the corrosive environment; the increment was even higher than that observed in the as-coated CS (AZ31B-cast-CSAA7075) specimens. The CS + EP specimen also exhibits better fatigue performance than the CS pure $\mathrm{Al}$ on $\mathrm{AZ31B}$ extrusion in the same $3.5 \% \mathrm{NaCl}$ solution [12,34]. Unlike the as-cast and as-coated specimens, the cyclic behavior of EP and CS + EP show a plateau in fatigue stress-life curves at the stress amplitudes of 50 and $80 \mathrm{MPa}$, respectively. In contrast, the CS specimen showed poor fatigue performance in the corrosive environment. This can be attributed to the presence of poor corrosion properties of AA7075 alloy itself. At the same time, the improvement of fatigue life in CS + EP can be correlated with the corrosion properties listed in Table 2 and Figure 5. The CS + EP specimen shows lower corrosion rates, which may be reduced the tendency of pit formation, resulting in a delay in the nucleation of cracks and prolonging the fatigue life. Similarly, the benefit of induced residual stress during CS has positive effects on fatigue life [59]. The fatigue life of CS is improved noticeably when compared to the bulk AZ31B cast and AZ31B extrusion specimens tested in a $3.5 \% \mathrm{NaCl}$ solution. However, it is worth mentioning that there was no runout ( $\left.>10^{7} \mathrm{cycles}\right)$ for those specimens in a corrosive environment, even at a lower stress amplitude of (40 MPa) which is equivalent to half of the compressive yield strength ( $90 \mathrm{MPa})$ and $16 \%$ of ultimate strength [11]. It should be mentioned that the composite nature of the cold spray coated specimens would cause higher surface stress in the stiffer $\mathrm{Al}$ coating, which can improve the fatigue properties in air as discussed in [35].

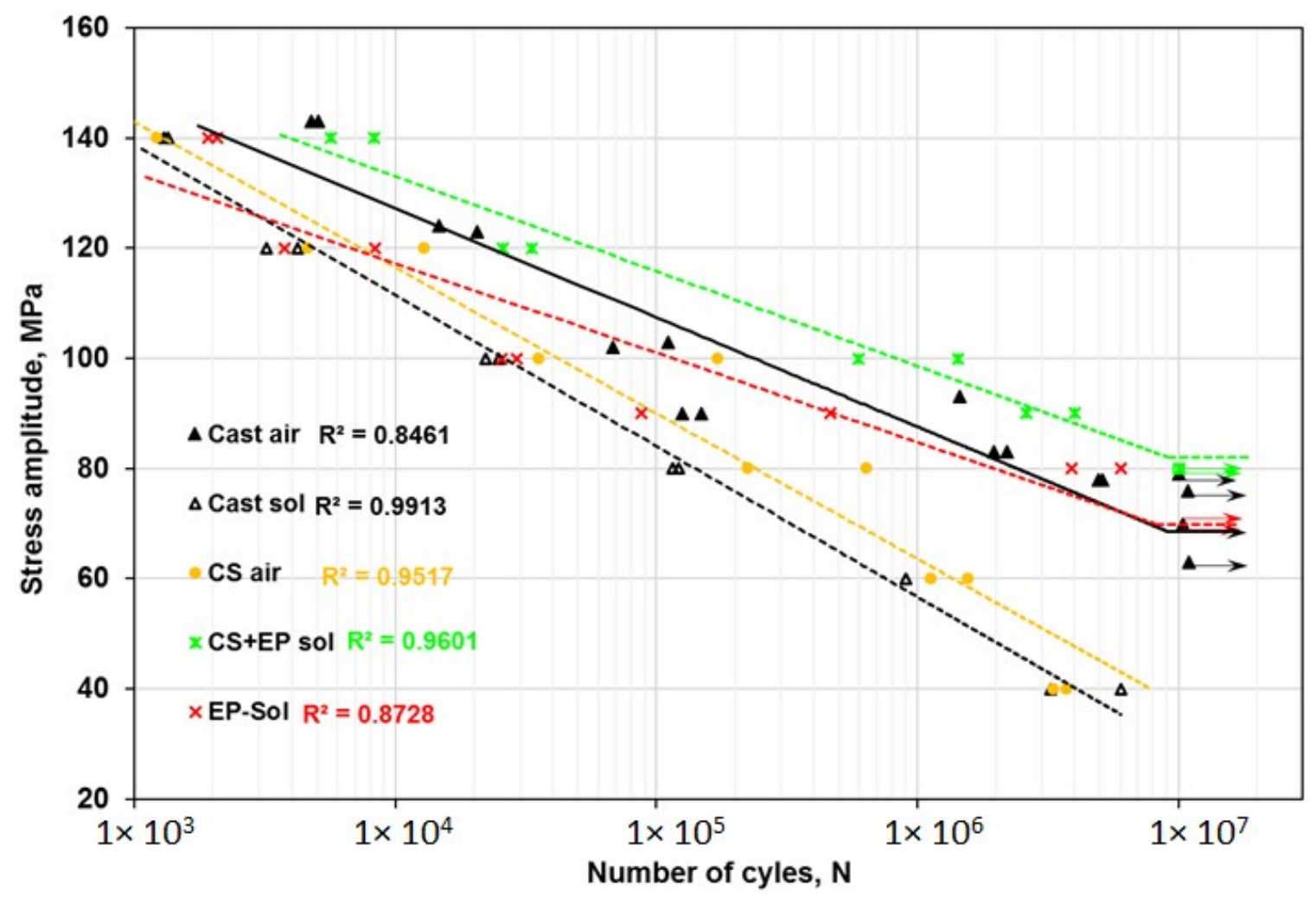

Figure 7. $S$ - $N$ curves show a comparison of fatigue life between the uncoated and coated AZ31B cast alloy tested in 3.5 wt.\% NaCl solution. Note: EP-e-paint, Sol-3.5\% NaCl solution and CS-cold spray.

\subsection{Fractographic Analysis}

The surface conditions of the as-processed and fatigue tested specimens after they reached their maximum fatigue life are presented in Figure $8 \mathrm{a}-\mathrm{c}$, respectively. Compared to the as a processed 
specimen (Figure 8a), there are no visible pits identified on the CS + EP specimen surfaces (Figure 8b) even after they reached the fatigue life of $10^{7}$ cycles in the $3.5 \% \mathrm{NaCl}$ solution. However, the surface of the CS specimen (Figure 8c) exhibits deep pits at multiple locations. Results of the XRD analysis of the corrosion products formed on the corrosion-fatigue specimen surfaces tested in the $3.5 \% \mathrm{NaCl}$ solution are shown in Figure 9.

As seen in Figure 9a, the corrosion product of $\mathrm{MgO}$ and $\mathrm{Mg}(\mathrm{OH})_{2}$ were identified in the EP specimen. In contrast, the CS specimen exhibited an additional phase of $\mathrm{Al}(\mathrm{OH})_{3}$ following the corrosion-fatigue test. This additional phase might form an unstable passive layer to improve the corrosion resistance. However, as discussed earlier, the presence of $\mathrm{Mg}$ and surface porosities are breaking the passive layer, which enhances the affinity of pore formation and leads to stress corrosion cracking.

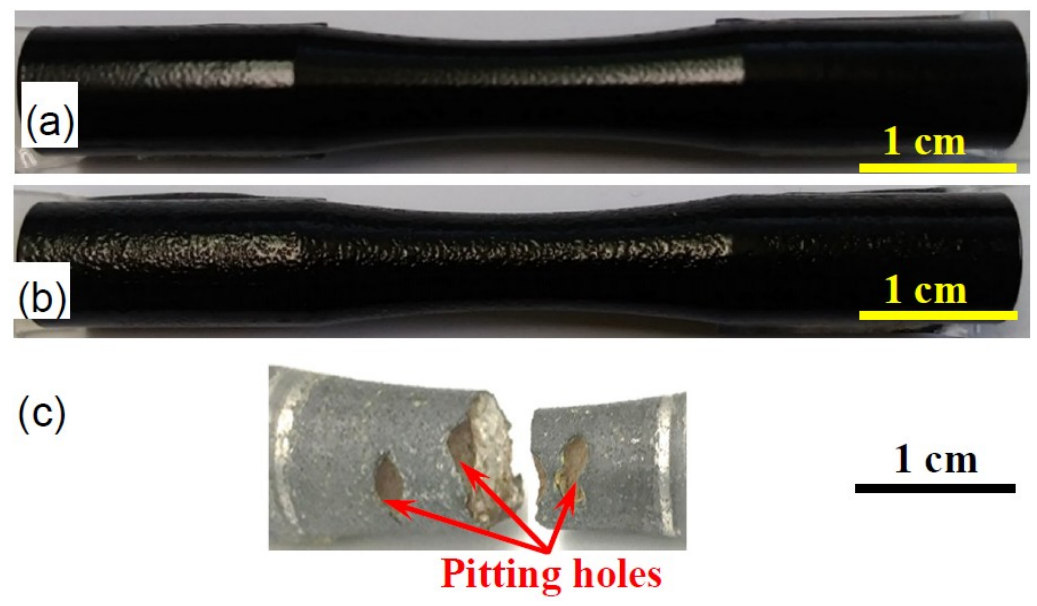

Figure 8. Surface topography of the AZ31B Mg alloy samples (a) before and $(\mathbf{b}, \mathbf{c})$ after corrosion fatigue tests: (a) CS + EP, (b) CS + EP sample after $10 \mathrm{M}$ cycles at a stress amplitude of $80 \mathrm{MPa}$ and (c) CS sample after $\sim 3.7$ million cycles at a stress amplitude of $40 \mathrm{MPa}$.

Figure 10 depicts the corrosion-fatigue fracture surfaces of the EP and CS + EP specimens tested at a stress amplitude of $90 \mathrm{MPa}$. The EP specimen, with a life around 0.5 million cycles, shows large corrosion pits (blue arrows in Figure 10a) with visible cracks in the oxides across the surface. In contrast, localized cavities (red arrow in Figure 10b) were identified on the CS + EP specimens at the life of $\sim 3$ million cycles, which permitted the $\mathrm{NaCl}$ solution to enter into the cavities and reacted with the interface of the substrate. Those pits raised and transformed to the large cavity, where the stress concentration occurred and finally resulted in the initiation of cracks. Multiple cracks emanating from open surface corrosion pits advancing along the final fracture zone were observed (Figure 10b). As identified in Figure 9, the oxides and hydroxides exhibit different morphologies on the fracture surfaces, as illustrated in Figure 11. The MgO shows porous-like morphology (Figure 11a) and $\mathrm{Mg}(\mathrm{OH})_{2}$ reveals spiked fibrous-like morphology (Figure 11b) in the EP specimen, while a denser $\mathrm{Al}(\mathrm{OH})_{3}$ was identified on the fracture surface of the CS + EP specimen. The presence of porous oxides acts as a source of stress concentration and the location of crack initiation. Thus, multiple cracks were formed. Then, the solution entered into the crack (Figure 11a) by creating further corrosion pits on the fracture surface, which accelerated the crack growth, resulting in failure.

As seen in Figure 11, the fatigue fracture surfaces of the specimens tested at lower stress amplitudes were fully covered with the corrosion products, which hid the fatigue fracture morphology. The specimens tested at higher stress amplitudes were further investigated to observe the fatigue fracture morphology. Figure 12 shows the magnified microstructure at different zones of the corrosion-fatigue fracture CS + EP specimen tested at the high-stress amplitude of $140 \mathrm{MPa}$. The slip bands (Figure 12a) were formed near the crack initiation zone, while the fatigue striation (Figure 12b) 
occurred at the crack advancing zones and the dimple-like morphology was the evident of the final fracture zone.

As depicted by Figure 12, corrosion products were visible in multiple locations. In addition, the anticipated typical ductile fracture voids on the fracture zone are visible. The corrosion products were also identified (yellow arrow in Figure 12a) which created micro pits nearby (red arrow in Figure 12c). The stress concentration caused by the pits and plastic deformation resulted in the growth of the pit to create a crack. The crack tips are eventually susceptible to corrosion resistance and formation of oxides. The plastic zone and high stresses at the tip of the crack fractured the oxide and protective layer, which in turn permitted the fresh metal to be exposed to the $\mathrm{NaCl}$ solution [60]. However, the chemical reaction at the interface of the substrate coating created local holes, which caused premature failure (Figure 11b). Thus, the combined action of corrosion and induced stress enhanced the progression of corrosion, which led to fracture at low stress amplitudes and deprived the fatigue performance of CS specimens in the corrosive environment.
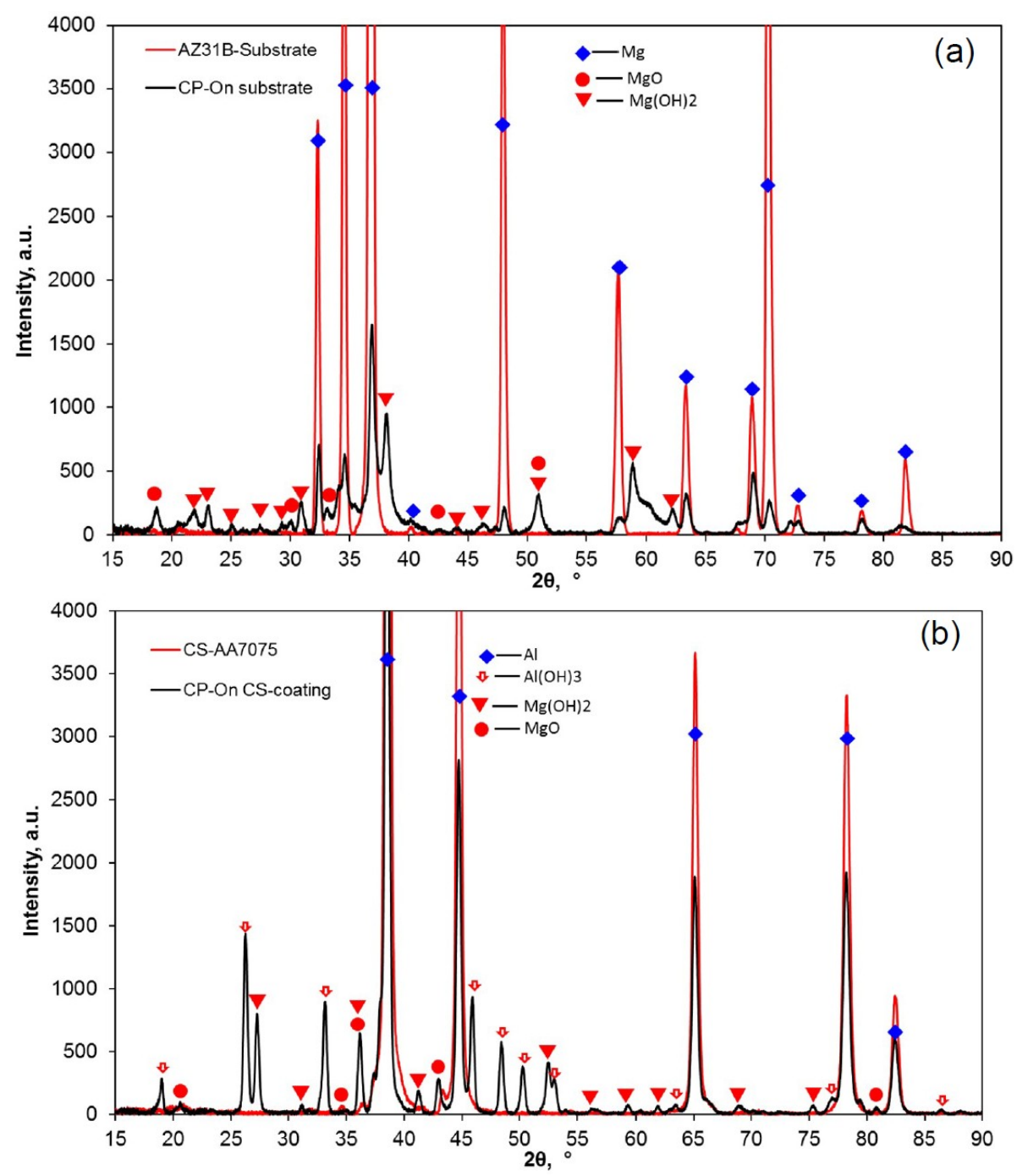

Figure 9. The $X$-ray diffraction $(X R D)$ analysis of the corrosion product $(\mathrm{CP})$ formed during fatigue test of AZ31B Mg alloy coated with AA7075 alloy; (a) CP on the substrate and (b) CP on the coat. 

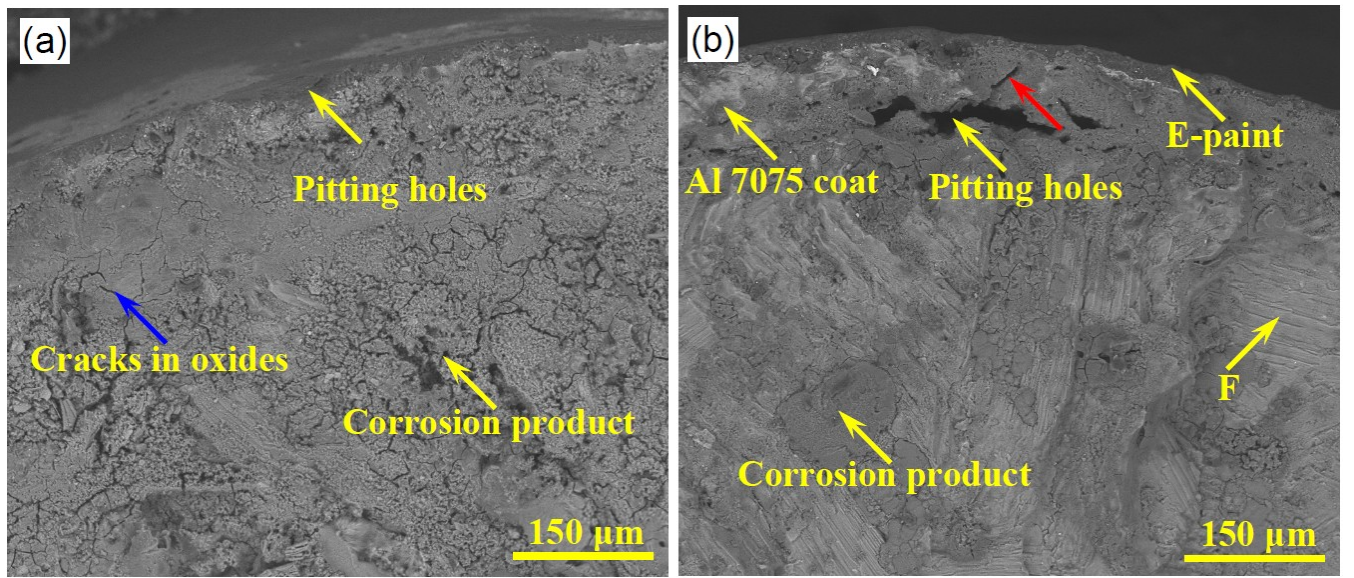

Figure 10. SEM images show the pitting holes leading to delamination on the fatigue fracture surfaces of the specimens tested at a stress amplitude of $90 \mathrm{MPa}(\mathbf{a}) \mathrm{EP}$ and (b) CS + EP.
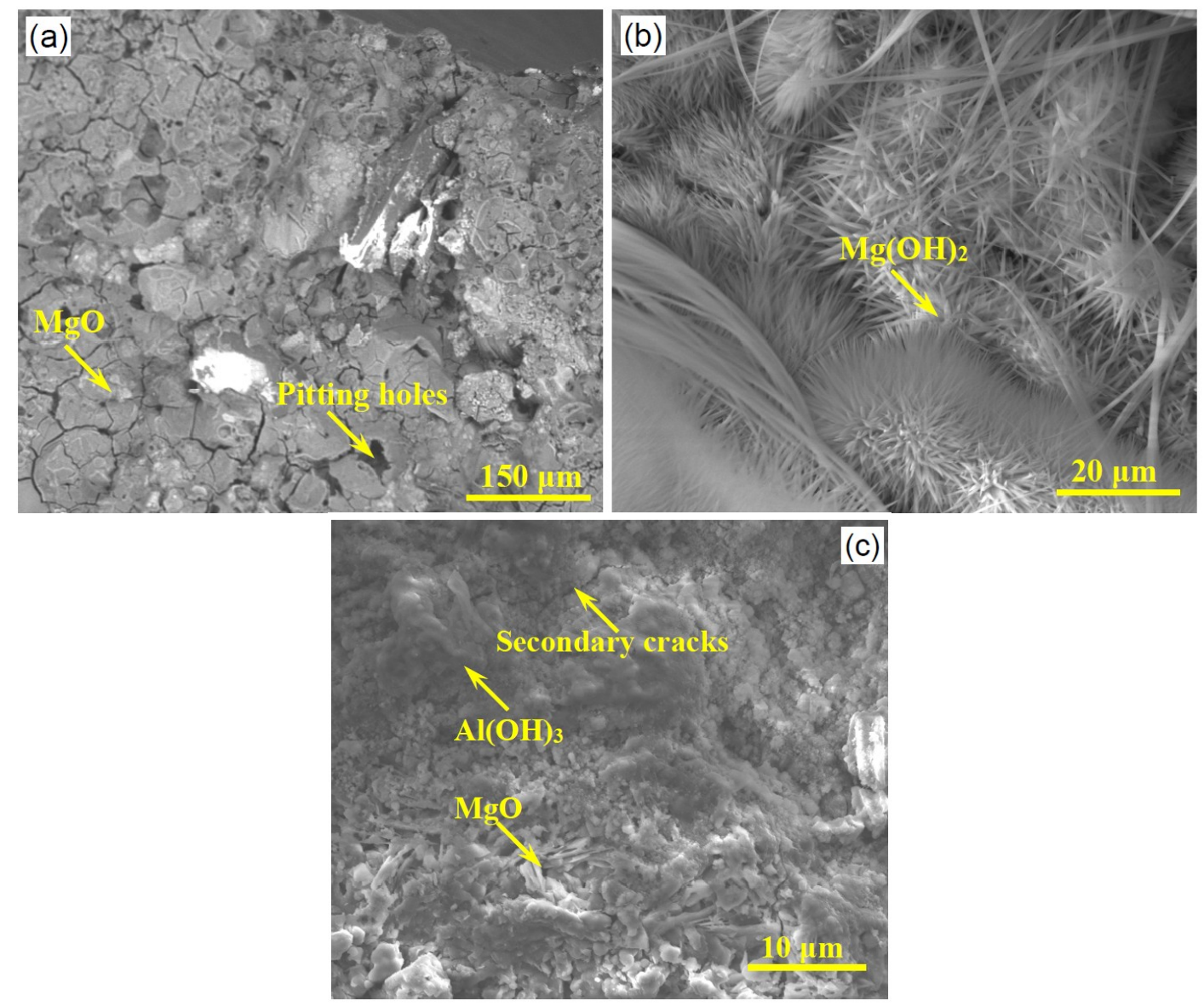

Figure 11. SEM images show the morphology of the corrosion products along with secondary cracks on fatigue fracture surface of the specimens tested at a stress amplitude of $90 \mathrm{MPa}$ in the $3.5 \% \mathrm{NaCl}$ solution (a) pitting holes with cracked oxides and (b) spiked fibrous-like $\mathrm{Mg}(\mathrm{OH})_{2}$, observed in EP specimens and (c) secondary cracks with porous $\mathrm{MgO}$ and dense $\mathrm{Al}(\mathrm{OH})_{3}$, identified in CS + EP specimens. 

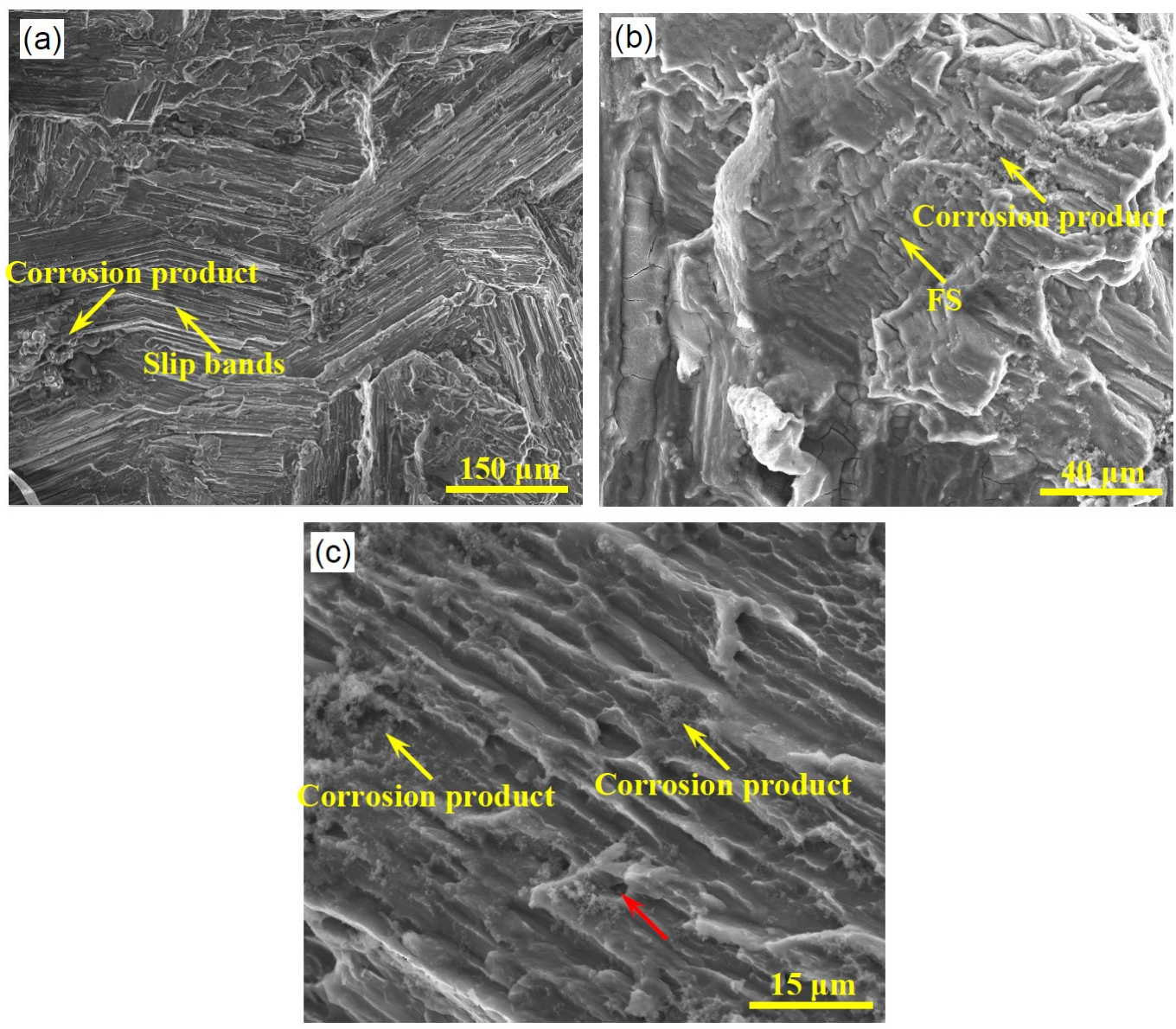

Figure 12. SEM images show the fatigue fracture surfaces of the CS + EP AZ31B Mg alloy specimen tested in the $3.5 \% \mathrm{NaCl}$ solution at a stress amplitude of $140 \mathrm{MPa}$ to investigate the morphology at different zones: (a) slip bands and (b) fatigue striation (FS) in the crack propagation zone and (c) final fracture zone showing tensile-like fracture morphology.

\section{Discussion}

Higher corrosion resistance and longer fatigue performance are always preferred in coating used to protect Mg alloys. In this study, the proposed combination of coatings (CS + EP) showed promising prospects. Finding out the root causes that control the corrosion resistance performance of the coatings can be helpful to further progress and enhance the fatigue performance. Usually, open pores, the chemistry of coating and developed microstructures are controlling the corrosion resistance leading to the superior fatigue performance $[57,61]$. In corrosion fatigue test, micro-cracks and pits are the common sites for nucleating and initiating the fatigue cracks. Those are enabling the nucleation and propagation of cracks leading to the premature failure, resulting in a short fatigue life. Similarly, the casting defects like porosity and reactive nature of $\mathrm{Mg}$ alloys accelerate the formation of pits that significantly lower the fatigue performance of cast AZ31B in $3.5 \% \mathrm{NaCl}$ solution. In contrast, due to the presence of compressive residual stress in CS specimens, the initiation of fatigue cracks was effectively hindered by closing the micro cracks. However, the formation of pits near the intermetallics in the AA7075 CS AA7075 coatings (as seen in Figure 8c) reduces the effectiveness of compressive residual stress results in a slight increase of fatigue life in CS AA7075 specimen in $3.5 \% \mathrm{NaCl}$. At the same time, due to excellent corrosion resistance, the pits were not visible at the surface of the CS + EP (Figure 8b), which shows superior fatigue performance of CS + EP specimens. It is also noticed that the EP coating is brittle in nature, which possess an excellent corrosion resistance in a stationary condition. However, they cannot exhibit similar corrosion resistance in cyclic loading. Thus, during cyclic loading, the mismatch between the EP and AZ31B substrate form an interfacial stress that 
generates cracks in the EP coating and lose the control of the corrosion protection results decreased the fatigue performance of EP specimens. Following sections discuss the details about the factors mentioned above that are affecting the corrosion fatigue performance of the studied specimens.

\subsection{Grain Refinement and Dislocation Density}

Grain size influences the corrosion resistances of CS coatings. Usually, small grains positively affect the corrosion resistance in $\mathrm{NaCl}$ corrosive media by forming a uniform passive film [62]. Moy et al. [63] and others [46,64] identified a significant grain refinement through dynamic recrystallization in the CS metallic coatings. In CS coatings, the refined grains were identified at the coating/substrate interface (as seen in Figure 4), which is limited. At the same time, the impact at higher velocity applied plastic deformation leading to adiabatic shear instability results in dynamic recrystallization which is basically limited to the inter-particle boundaries [57]. However, due to the pinning effect of intermetallics, there was no visible grain refinement identified at the particles interface in the CS coating (Figure $4 \mathrm{~d}$ ). Thus, the improvement of corrosion resistance by grain refinement may not be impacted much in CS coating of the AA7075 alloy.

As seen in Figures 5 and 6 and as listed in Tables 2-4, the CS + EP obtained superior performance in corrosion resistance followed by CS AA7075, while substrate shows significantly lower or similar corrosion resistance to the CS AA7075. Similarly, the fatigue performance of the specimens in different conditions follow the same trend as the corrosion test; i.e., CS + EP to cast AZ31B obtained higher to lower fatigue lives, respectively. Studies show that a significant plastic deformation is achieved by the particle impact-induced deformation in the CS coatings, which induced the lattice micro-strain leading to a substantial dislocation multiplication $[57,65]$. It was reported that the defects like dislocations reduce the electron work function which decreases the energy barrier to conduct electrochemical reactions [66]. It was also stated that the dislocation density can create active sites on the specimen surface and consequently enhance the corrosion rate [67]. Balani et al. [68] and others [32,47,69] reported that CS of $\mathrm{Al}$ coatings exhibits a higher density of dislocations which acted as a potential active site of the pit formations results in lower corrosion resistance. Similarly, the interfacial deformation among the particles at higher strain rate on the CS AA7075 coating specimens can lead to the favored electrochemical reaction zone. Therefore, a high dislocation density in CS coatings shows an adverse effect on the corrosion fatigue performance.

\subsection{Residual Stress}

Compressive residual stresses also play a role in the corrosion resistance specifically the pits formation. The residual stresses are formed in CS coatings because of peening effect by higher particle impact velocity [27] and the thermal expansion mismatch of the coating and the substrate [46]. As the impact velocity and carrier gas temperature are very high, the striking of the CS coating particles on the AZ31B substrate induced plastic deformation due to the adiabatic shear instability adjacent to the surface of the impacted particles, resulting in the formation of residual stress $[20,59,70]$. At the same time, the thermal expansion coefficient mismatch between the AA7075 coating and AZ31B substrate significantly affect the formation of residual stress [60]. During the CS, the carrier gas temperature was $400{ }^{\circ} \mathrm{C}$ and because of higher values of thermal expansion of $\mathrm{Al}$-matrix relative to Mg-matrix, the expansion mismatch at the interface results in a higher magnitude of compressive stress. In our earlier work [35], we presented the measured residual stress induced by CS AA7075 on the as-cast AZ31B substrate. Results demonstrated that the residual stress due to the thermal expansion coefficient mismatch and the impact of CS particles on the as-cast uncoated was as high as-122 MPa in the AA7075 coatings (higher than the CS pure Al on AZ31B extrusion substrate [12]) [35]. The presence of high compressive residual stress at the specimen surface suppressed the crack initiation and its propagation, which eventually improved the fatigue performance of CS as-cast AZ31B in the air. In general, when the specimens are tested in a corrosive environment, micro-cracks are formed which work as a transportation pathway to penetrate the electrolyte/solution to the fresh materials 
which remarkably degrades the corrosion fatigue performance. In CS AA7075, the presence of the compressive residual stresses positively affects the corrosion resistance by closing the micro-cracks, which form vertical to the coating surface $[12,58]$. As the micro-cracks were closed, the solution was not able to enter for further corrosion results in increasing the fatigue life of the CS AA7075 compared to the bare substrate cast AZ31B.

\subsection{Effect of Intermetallics on Fatigue Performance}

The presence of intermetallics also influences the electrochemical reaction of the materials by forming local cell action at the grain boundaries. The formation of the local cells depends on the potential of the matrix and the intermetallics [71,72]. The intermetallic $\mathrm{MgZn}_{2}$ present in coating material AA7075 is less noble than the Al-matrix. They will be acted as anodes and the Al-matrix acted as cathode in $\mathrm{NaCl}$ solution. Sun et al. [71] reported that shot peening can dissolve the nano-precipitates like $\mathrm{MgZn}_{2}$ into $\mathrm{Al}$ matrix, which form a homogeneous microstructure that reduces the vulnerability of corrosion. As seen in Figure 4, the intermetallics of $\mathrm{MgZn}_{2}$ was identified which form local cells in the coating leading to the formation of pits (Figure 8c). Reboul et al. [73] and Sun et al. [71] reported that to avoid the pits repassivation, a critical $\mathrm{Cl}^{-}$and $\mathrm{H}^{+}$concentration is required to obtain the propagating pits stabilizations. When the localized cells are formed, a concentrated $\mathrm{AlCl}_{3}$ solution having $\mathrm{pH}$ of 3 is produced in the pits. The pit will continue to propagate as long as the local galvanic cells are able to maintain the concentration of the solution within the pit more quickly than the diffusion of hydrogen bubbles tend to dilute corresponding pits. Therefore, the pits formed in CS coating due to the presence of $\mathrm{MgZn}_{2}$ intermetallic were not able to close by the compressive residual stress, resulting in slightly increased fatigue life in corrosive environment. In contrast, the presences of zinc phosphate on the CS coatings (CS + EP) or cast AZ31B substrate decreased the dissolution rate of the materials which preventing the formation of localized galvanic corrosion cell. As the pits were not forming around the intermetallics, the corrosion resistance of the top-coated specimens increased subsequently enhanced the fatigue life.

\subsection{Other Factors Affecting the Fatigue Performance}

The improvement of fatigue life can also be influenced by several other factors, including higher fatigue resistance of the coating material AA7075 and high bonding strength between AA7075 and AZ31B cast. AA7075 has higher fatigue resistance than AZ31B cast [36]. Therefore, the surface cracking in the CS + EP is delayed until higher stresses are experienced. The possibility of the formation of sub-surface cracks in AZ31B, leading to fracture at lower stresses, is reduced in CS AA7075, because any premature cracks on AZ31B are proven to be non-propagating cracks [36]. In addition, the coatings (CS or EP) covered/ filled the defects like casting porosities, which delayed cracks nucleation, results in improvement in fatigue life. At the same time, the obtained higher bonding strength also reduced the tendency of delamination of the coating, also exhibiting longer fatigue life.

In brief, the peening-effect induced compressive residual stresses supposed have a significant effect on the corrosion fatigue performance. However, the presence of intermetallics and the highly dense dislocation are responsible for lowering the corrosion resistance subsequently the corrosion fatigue life of the CS AA7075. In contrast, EP were obtained significant corrosion fatigue resistance due to the outstanding corrosion protection of the zinc phosphate top coat, while the CS + EP obtained superior corrosion fatigue performance due to the excellent corrosion resistance of the top coating in addition to the presence of compressive residual stress. Moreover, as discussed earlier, the e-painted specimen does not affect the tensile properties of the cold spray specimen. As the e-coating materials possess better corrosion properties, which prevented the formation of pits around the intermetallics, which in turn improved the corrosion fatigue life. 


\section{Conclusions}

The corrosion-fatigue properties of a CS AA7075 and e-paint cast AZ31B in a 3.5\% NaCl solution at room temperature were studied. Based on the results of this study and the above discussion, the following conclusions can be drawn:

- $\quad$ TEM microstructural analysis identified a continuous interfacial layer with a mixture of $\mathrm{Al}$ and $\mathrm{Mg}$ having a thickness of 200-300 nm. At the same time, ladder and columnar-like grain morphologies were observed in the AA7075 coating and AZ31B substrate at the interface.

- The electrochemical corrosion analysis shows that the corrosion resistance of the CS AA7075 alloy on AZ31B did not provide a significant improvement; this can be attributed to the fact that the compressive residual stress induced by the CS coating were suppressed by formation of corrosion pits and the presence of intermetallic. However, when the e-painting top coat was added to the CS coating it provided a corrosion resistance remarkably higher that of the AZ31B.

- A significant enhancement in fatigue life in the CS AA7075 followed by e-painted specimens was identified. This can be attributed due to the existence of passive oxide layer that increase the corrosion resistance. In addition, the high strength of the AA7075 alloy delayed the cracking in the coating of the e-painted and coated specimens. However, the CS coating without e-paint exhibited early cracking due to pit formation that acted as a pathway for $\mathrm{NaCl}$ to penetrate into the interface, creating localized pits. The localized pits led to stress concentration, which resulted in the nucleation of cracks caused a premature failure of the AZ31B substrate and hence lower fatigue life of the as-coated specimen.

- The fatigue life of the EP samples was lower than the CS + EP sample as there was no induced compressive residual stress and the brittle nature of the EP.

- The application of an e-paint on top of the CS coat proved to enhance significantly the corrosion-fatigue life of AZ31B cast.

Author Contributions: The conceptualization of the research was directed by H.J.; The methodology and fatigue tests were performed by S.B.D.; Literature review and data analysis in corrosion field were performed by Y.X.; Fractography and SEM analysis were achieved by S.K.S. under supervision of X.P.; Data analysis of fatigue tests was compiled by S.B.D. and validated by H.J.; Writing-original draft preparation, S.K.S. and S.B.D.; Writing-Review \& Editing, H.J.; Visualization, X.P.; Supervision, Administration, and Funding Acquisition, H.J.

Funding: This research was funded by the Natural Sciences and Engineering Research Council of Canada (NSERC), Automotive Partnership Canada (APC) program (APCPJ 459269-13). The APC was in partnership with Multimatic Technical Centre, Ford Motor Company, Centerline Windsor and CanmetMATERIALS.

Acknowledgments: The authors would also like to thank Rudy Bowers and MetoKote Canada Limited, Cambridge Ontario, for the e-coating.

Conflicts of Interest: The authors declare no conflict of interest. The funders had no role in the design of the study; in the collection, analyses, or interpretation of data; in the writing of the manuscript, and in the decision to publish the results.

\section{References}

1. Karparvarfard, S.M.H.; Shaha, S.K.; Behravesh, S.B.; Jahed, H.; Williams, B.W. Microstructure, texture and mechanical behavior characterization of hot forged cast ZK60 magnesium alloy. J. Mater. Sci. Technol. 2017, 33, 907-918. [CrossRef]

2. Joost, W.J.; Krajewski, P.E. Towards magnesium alloys for high-volume automotive applications. Scr. Mater. 2017, 128, 107-112. [CrossRef]

3. Bhuiyan, M.S.; Mutoh, Y.; Murai, T.; Iwakami, S. Corrosion fatigue behavior of extruded magnesium alloy AZ80-T5 in a 5\% NaCl environment. Eng. Fract. Mech. 2010, 77, 1567-1576. [CrossRef]

4. Liao, J.; Hotta, M.; Yamamoto, N. Corrosion behavior of fine-grained AZ31B magnesium alloy. Corros. Sci. 2012, 61, 208-214. [CrossRef]

5. Kulekci, M.K. Magnesium and its alloys applications in automotive industry. Int. J. Adv. Manuf. Technol. 2008, 39, 851-865. [CrossRef] 
6. Wang, S.D.; Xu, D.K.; Wang, B.J.; Han, E.H.; Dong, C. Effect of solution treatment on the fatigue behavior of an as-forged Mg-Zn-Y-Zr alloy. Sci. Rep. 2016, 6, 23955. [CrossRef] [PubMed]

7. Jahed, H.; Albinmousa, J. Multiaxial behaviour of wrought magnesium alloys-A review and suitability of energy-based fatigue life model. Theor. Appl. Fract. Mech. 2014, 73, 97-108. [CrossRef]

8. Behravesh, S.B.; Jahed, H.; Lambert, S.B.; Chengji, M. Constitutive modeling for cyclic behavior of AZ31B magnesium alloy and its application. Adv. Mater. Res. 2014, 891, 809-814. [CrossRef]

9. Roostaei, A.A.; Jahed, H. Role of loading direction on cyclic behaviour characteristics of AM30 extrusion and its fatigue damage modelling. Mater. Sci. Eng. 2016, 670, 26-40. [CrossRef]

10. Pan, F.; Yang, M.; Chen, X. A review on casting magnesium alloys: Modification of commercial alloys and development of new alloys. J. Mater. Sci. Technol. 2016, 32, 1211-1221. [CrossRef]

11. Toscano, D.; Shaha, S.K.; Behravesh, B.; Jahed, H.; Williams, B. Effect of forging on microstructure, texture, and uniaxial properties of cast AZ31B alloy. J. Mater. Eng. Perform. 2017, 26, 3090-3103. [CrossRef]

12. Diab, M.; Pang, X.; Jahed, H. The effect of pure aluminum cold spray coating on corrosion and corrosion fatigue of magnesium (3\% Al-1\% Zn) extrusion. Surf. Coat. Technol. 2017, 309, 423-435. [CrossRef]

13. Eliezer, A.; Medlinsky, O.; Haddad, J.; Ben-Hamu, G. Corrosion fatigue behavior of magnesium alloys under oil environments. Mater. Sci. Eng. A 2008, 477, 129-136. [CrossRef]

14. Raman, R.S.; Jafari, S.; Harandi, S.E. Corrosion fatigue fracture of magnesium alloys in bioimplant applications: A review. Eng. Fract. Mech. 2015, 137, 97-108. [CrossRef]

15. Unigovski, Y.; Eliezer, A.; Abramov, E.; Snir, Y.; Gutman, E.M. Corrosion fatigue of extruded magnesium alloys. Mater. Sci. Eng. A 2003, 360, 132-139. [CrossRef]

16. Eliezer, A.; Gutman, E.M.; Abramov, E.; Unigovski, Y. Corrosion fatigue of die-cast and extruded magnesium alloys. J. Light Met. 2001, 1, 179-186. [CrossRef]

17. Gutman, E.M.; Eliezer, A.; Unigovski, Y.; Abramov, E. Mechanoelectrochemical behavior and creep corrosion of magnesium alloys. Mater. Sci. Eng. A 2001, 302, 63-67. [CrossRef]

18. Ibrahim, M.E.; Zhuang, W.Z. Nondestructive inspection of fatigue crack propagation beneath supersonic particle deposition coatings during fatigue testing. Int. J. Fatigue 2017, 102, 149-157. [CrossRef]

19. Bu, H.; Yandouzi, M.; Lu, C.; MacDonald, D.; Jodoin, B. Cold spray blended $\mathrm{Al}+\mathrm{Mg}_{17} \mathrm{Al}_{12}$ coating for corrosion protection of AZ91D magnesium alloy. Surf. Coat. Technol. 2012, 207, 155-162. [CrossRef]

20. Ghelichi, R.; MacDonald, D.; Bagherifard, S.; Jahed, H.; Guagliano, M.; Jodoin, B. Microstructure and fatigue behavior of cold spray coated Al5052. Acta Mater. 2012, 60, 6555-6561. [CrossRef]

21. Rokni, M.R.; Widener, C.A.; Crawford, G.A.; West, M.K. An investigation into microstructure and mechanical properties of cold sprayed $7075 \mathrm{Al}$ deposition. Mater. Sci. Eng. A 2015, 625, 19-27. [CrossRef]

22. Shayegan, G.; Mahmoudi, H.; Ghelichi, R.; Villafuerte, J.; Wang, J.; Guagliano, M.; Jahed, H. Residual stress induced by cold spray coating of magnesium AZ31B extrusion. Mater. Des. 2014, 60, 72-84. [CrossRef]

23. Spencer, K.; Fabijanic, D.M.; Zhang, M.X. The use of $\mathrm{Al}_{-} \mathrm{Al}_{2} \mathrm{O}_{3}$ cold spray coatings to improve the surface properties of magnesium alloys. Surf. Coat. Technol. 2009, 204, 336-344. [CrossRef]

24. Wang, Q.; Qiu, D.; Xiong, Y.; Birbilis, N.; Zhang, M.X. High resolution microstructure characterization of the interface between cold sprayed Al coating and Mg alloy substrate. Appl. Surf. Sci. 2014, 289, 366-369. [CrossRef]

25. Assadi, H.; Kreye, H.; Gärtner, F.; Klassen, T. Cold spraying-A materials perspective. Acta Mater. 2016, 116, 382-407. [CrossRef]

26. Moridi, A.; Hassani-Gangaraj, S.M.; Guagliano, M.; Vezzu, S. Effect of cold spray deposition of similar material on fatigue behavior of Al 6082 alloy. Fract. Fatigue 2014, 7, 51-57.

27. Luo, X.T.; Li, C.X.; Shang, F.L.; Yang, G.J.; Wang, Y.Y.; Li, C.J. High velocity impact induced microstructure evolution during deposition of cold spray coatings: A review. Surf. Coat. Technol. 2014, 254, 11-20. [CrossRef]

28. McCune, R.C.; Donlon, W.T.; Popoola, O.O.; Cartwright, E.L. Cartwright characterization of copper layers produced by cold gas-dynamic spraying. J. Therm. Spray Technol. 2000, 9, 73-82. [CrossRef]

29. Hassani-Gangaraj, S.M.; Moridi, A.; Guagliano, M. Critical review of corrosion protection by cold spray coatings. Surf. Eng. 2015, 31, 803-815. [CrossRef]

30. Yandouzi, M.; Richer, P.; Jodoin, B. SiC particulate reinforced Al-12Si alloy composite coatings produced by the pulsed gas dynamic spray process: Microstructure and properties. Surf. Coat. Technol. 2009, 203, 3260-3270. [CrossRef] 
31. Lee, H.Y.; Jung, S.H.; Lee, S.Y.; You, Y.H.; Ko, K.H. Correlation between $\mathrm{Al}_{2} \mathrm{O}_{3}$ particles and interface of

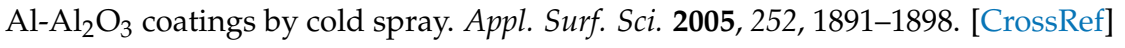

32. Tao, Y.; Xiong, T.; Sun, C.; Kong, L.; Cui, X.; Li, T.; Song, G.L. Microstructure and corrosion performance of a cold sprayed aluminium coating on AZ91D magnesium alloy. Corros. Sci. 2010, 52, 3191-3197. [CrossRef]

33. Tao, Y.; Xiong, T.; Sun, C.; Jin, H.; Du, H.; Li, T. Effect of $\alpha-\mathrm{Al}_{2} \mathrm{O}_{3}$ on the properties of cold sprayed $\mathrm{Al} / \alpha-\mathrm{Al}_{2} \mathrm{O}_{3}$ composite coatings on AZ91D magnesium alloy. Appl. Surf. Sci. 2009, 256, 261-266. [CrossRef]

34. Kalatehmollaei, E.; Mahmoudi-Asl, H.; Jahed, H. An asymmetric elastic-plastic analysis of the load-controlled rotating bending test and its application in the fatigue life estimation of wrought magnesium AZ31B. Int. J. Fatigue 2014, 64, 33-41. [CrossRef]

35. Dayani, S.B.; Shaha, S.K.; Ghelichi, R.; Wang, J.F.; Jahed, H. The impact of AA7075 cold spray coating on the fatigue life of AZ31B cast alloy. Surf. Coat. Technol. 2018, 337, 150-158. [CrossRef]

36. Niu, L.Y.; Jiang, Z.H.; Li, G.Y.; Gu, C.D.; Lian, J.S. A study and application of zinc phosphate coating on AZ91D magnesium alloy. Surf. Coat. Technol. 2006, 200, 3021-3026. [CrossRef]

37. Bastos, A.C.; Ferreira, M.G.S.; Simoes, A.M. Comparative electrochemical studies of zinc chromate and zinc phosphate as corrosion inhibitors for zinc. Prog. Org. Coat. 2005, 52, 339-350. [CrossRef]

38. Mahdavian, M.; Attar, M.M. Evaluation of zinc phosphate and zinc chromate effectiveness via AC and DC methods. Prog. Org. Coat. 2005, 53, 191-194. [CrossRef]

39. Beiro, M.; Collazo, A.; Izquierdo, M.; Nóvoa, X.R.; Pérez, C. Characterisation of barrier properties of organic paints: The zinc phosphate effectiveness. Prog. Org. Coat. 2003, 46, 97-106. [CrossRef]

40. Davies, J.M. Lung cancer mortality among workers making lead chromate and zinc chromate pigments at three English factories. Occup. Environ. Med. 1984, 41, 158-169. [CrossRef]

41. Hu, R.G.; Zhang, S.; Bu, J.F.; Lin, C.J.; Song, G.L. Progress in organic coatings recent progress in corrosion protection of magnesium alloys by organic coatings. Prog. Org. Coat. 2011, 73, 129-141. [CrossRef]

42. Langård, S.; Norseth, T. A cohort study of bronchial carcinomas in workers producing chromate pigments. Occup. Environ. Med. 1975, 32, 62-65. [CrossRef]

43. ASTM E8 / E8M-11: Standard Test Methods for Tension Testing of Metallic Materials; ASTM International: West Conshohocken, PA, USA, 2011.

44. E-Coat Process Specifics. Available online: https://www.ppgcoatingsservices.com/services/electrocoating/ e-coat-process-specifics (accessed on 20 July 2018).

45. Ezhilselvi, V.; Nithin, J.; Balaraju, J.N.; Subramanian, S. The influence of current density on the morphology and corrosion properties of MAO coatings on AZ31B magnesium alloy. Surf. Coat. Technol. 2016, 288, 221-229. [CrossRef]

46. Marzbanrad, B.; Jahed, H.; Toyserkani, E. On the evolution of substrate's residual stress during cold spray process: A parametric study. Mater. Des. 2018, 138, 90-102. [CrossRef]

47. Dzhurinskiy, D.; Maeva, E.; Leshchinsky, E.; Maev, R.G. Corrosion protection of light alloys using low pressure cold spray. J. Therm. Spray Technol. 2012, 21, 304-313. [CrossRef]

48. Zhu, L.; Song, G. Improved corrosion resistance of AZ91D magnesium alloy by an aluminium-alloyed coating. Surf. Coat. Technol. 2006, 200, 2834-2840. [CrossRef]

49. McCafferty, E. Validation of corrosion rates measured by the Tafel extrapolation method. Corros. Sci. 2005, 47, 3202-3215. [CrossRef]

50. Wagner, C. On the interpretation of corrosion processes through the superposition of electrochemical partial processes and on the potential of mixed electrodes. Ztschr. Elecktrochem 1938, 44, 391. [CrossRef]

51. Meng, G.; Li, Y.; Shao, Y.; Zhang, T.; Wang, Y.; Wang, F.; Cheng, X.; Dong, C.; Li, X. Effect of microstructures on corrosion behavior of nickel coatings: (II) competitive effect of grain size and twins density on corrosion behavior. J. Mater. Sci. Technol. 2016, 32, 465-469. [CrossRef]

52. Quach, N.C.; Uggowitzer, P.J.; Schmutz, P. Corrosion behaviour of an Mg-Y-RE alloy used in biomedical applications studied by electrochemical techniques. C.R. Chim. 2008, 11, 1043-1054. [CrossRef]

53. Niu, Y.; Cui, R.; He, Y.; Yu, Z. Wear and corrosion behavior of Mg-Gd-Y-Zr alloy treated by mixed molten-salt bath. J. Alloy. Compd. 2014, 610, 294-300. [CrossRef]

54. Hussein, R.O.; Zhang, P.; Nie, X.; Xia, Y.; Northwood, D.O. The effect of current mode and discharge type on the corrosion resistance of plasma electrolytic oxidation (PEO) coated magnesium alloy AJ62. Surf. Coat. Technol. 2011, 206, 1990-1997. [CrossRef] 
55. Rammelt, U.; Reinhard, G. On the applicability of a constant phase element (CPE) to the estimation of roughness of solid metal electrodes. Electrochim. Acta 1990, 35, 1045-1049. [CrossRef]

56. Nady, H.; El-Rabiei, M.M.; Samy, M. Corrosion behavior and electrochemical properties of carbon steel, commercial pure titanium, copper and copper-aluminum-nickel alloy in 3.5\% sodium chloride containing sulfide ions. Egypt. J. Pet. 2017, 26, 79-94. [CrossRef]

57. Wei, Y.K.; Li, Y.J.; Zhang, Y.; Luo, X.T.; Li, C.J. Corrosion resistant nickel coating with strong adhesion on AZ31B magnesium alloy prepared by an in-situ shot-peening-assisted cold spray. Corros. Sci. 2018, 138, 105-115. [CrossRef]

58. Mahdavian, M.M.; Attar, M.M. Another approach in analysis of paint coatings with EIS measurement: Phase angle at high frequencies. Corros. Sci. 2006, 48, 4152-4157. [CrossRef]

59. Jahed, H.; Ghelichi, R. Residual stresses and fatigue life enhancement of cold spray. Mod. Cold Spray 2015, 225-252.

60. Nan, Z.Y.; Ishihara, S.; Goshima, T. Corrosion fatigue behavior of extruded magnesium alloy AZ31 in sodium chloride solution. Int. J. Fatigue 2008, 30, 1181-1188. [CrossRef]

61. Xie, Z.H.; Chen, F.; Xiang, S.R.; Zhou, J.L.; Song, Z.W.; Yu, G. Studies of several pickling and activation processes for electroless Ni-P plating on AZ31 magnesium alloy. J. Electrochem. Soc. 2015, 162, D115-D123. [CrossRef]

62. Wang, S.G.; Huang, Y.J.; Han, H.B.; Sun, M.; Long, K.; Zhang, Z.D. The electrochemical corrosion characterization of bulk nanocrystalline aluminium by X-ray photoelectron spectroscopy and ultra-violet photoelectron spectroscopy. J. Electroanal. Chem. 2014, 724, 95-102. [CrossRef]

63. Moy, C.K.; Cairney, J.; Ranzi, G.; Jahedi, M.; Ringer, S.P. Investigating the microstructure and composition of cold gas-dynamic spray (CGDS) Ti powder deposited on Al 6063 substrate. Surf. Coat. Technol. 2010, 204, 3739-3749. [CrossRef]

64. Zou, Y.; Qin, W.; Irissou, E.; Legoux, J.G.; Yue, S.; Szpunar, J.A. Dynamic recrystallization in the particle/particle interfacial region of cold-sprayed nickel coating: Electron backscatter diffraction characterization. Scr. Mater. 2009, 61, 899-902. [CrossRef]

65. Koivuluoto, H.; Honkanen, M.; Vuoristo, P. Cold-sprayed copper and tantalum coatings—detailed FESEM and TEM analysis. Surf. Coat. Technol. 2010, 204, 2353-2361. [CrossRef]

66. Li, W.; Li, D.Y. Variations of work function and corrosion behaviors of deformed copper surfaces. Appl. Surf. Sci. 2005, 240, 388-395. [CrossRef]

67. Laleh, M.; Kargar, F. Effect of surface nanocrystallization on the microstructural and corrosion characteristics of AZ91D magnesium alloy. J. Alloy. Compd. 2011, 509, 9150-9156. [CrossRef]

68. Balani, K.; Laha, T.; Agarwal, A.; Karthikeyan, J.; Munroe, N. Effect of carrier gases on microstructural and electrochemical behavior of cold-sprayed 1100 aluminum coating. Surf. Coat. Technol. 2005, 195, 272-279. [CrossRef]

69. Meydanoglu, O.; Jodoin, B.; Kayali, E.S. Microstructure, mechanical properties and corrosion performance of $7075 \mathrm{Al}$ matrix ceramic particle reinforced composite coatings produced by the cold gas dynamic spraying process. Surf. Coat. Technol. 2013, 235, 108-116. [CrossRef]

70. Ghelichi, R.; Bagherifard, S.; Mac Donald, D.; Brochu, M.; Jahed, H.; Jodoin, B.; Guagliano, M. Fatigue strength of $\mathrm{Al}$ alloy cold sprayed with nanocrystalline powders. Int. J. Fatigue 2014, 65, 51-57. [CrossRef]

71. Sun, Q.; Liu, X.; Han, Q.; Li, J.; Xu, R.; Zhao, K. A comparison of AA2024 and AA7150 subjected to ultrasonic shot peening: Microstructure, surface segregation and corrosion. Surf. Coat. Technol. 2018, 337, 552-560. [CrossRef]

72. Sun, Q.; Han, Q.; Xu, R.; Zhao, K.; Li, J. Localized corrosion behaviour of AA7150 after ultrasonic shot peening: Corrosion depth vs. impact energy. Corros. Sci. 2018, 130, 218-230. [CrossRef]

73. Reboul, M.C.; Warner, T.J.; Mayer, H.; Barouk, B. A Ten Step Mechanism for the Pitting Corrosion of Aluminium Alloys. Corros. Rev. 1997, 15, 471-496. [CrossRef]

(C) 2018 by the authors. Licensee MDPI, Basel, Switzerland. This article is an open access article distributed under the terms and conditions of the Creative Commons Attribution (CC BY) license (http:/ / creativecommons.org/licenses/by/4.0/). 